\title{
LAS SOCIEDADES CELTIBÉRICA Y LUSITANA Y LA ESCRITURA
}

\author{
POR
}

\author{
JAVIER DE HOZ \\ Departamento de Filologia Griega. Universidad Complutense
}

\section{RESUMEN}

No hay un uso lusitano de la escritura, sino un uso ocasional del alfabeto latino para escribir lusitano. El caso celtibérico es muy diferente. Existe un modelo de uso de la escritura muy generalizado en el Mediterráneo antiguo con anterioridad a la expansión del modelo creado en la Atenas clásica. El uso celtibérico de la escritura, que aqui se ilustra en las distintas categorias de texto que se nos han conservado, se integra en ese modelo, que en sus diversas variantes ha podido servir a sociedades de tipos bastante diversos. La cuestión está relacionada con la del origen del uso de la escritura entre los celtiberos, y la influencia latina en ese uso, pero por el momento no cabe dar una explicacación segura de estos problemas sino tan sólo plantear hipótesis alternativas.

\section{SUMMARY}

Lusitanian literacy did not exist, only occasional writing of Lusitanian texts in Latin alphabet, in contrast with the Celtiberian situation. There is a literacy model quite usual in the Mediterranean lands before the generalization of the Classical Athenian model. Celtiberian literacy, illustated in this paper trough the various kinds of texts recovered, belongs to that model. Another aspects of Celtiberian literacy are its origin. as a different question from the origing of the writing-system, and the influence exerced by the Romans. These problems are not yet amenable to a solution, but alternative hypothesis are presented.

1. En un artículo anterior me he ocupado de los usos de la escritura en las sociedades del área no indoeuropea de Hispania, de cómo esos usos se explican en un contexto social determinado y de cómo distintos modos de vida han dado lugar a distintos tipos de textos y distintas formas de utilizar la escritura $^{\prime}$. En éste pretendo hacer lo mismo con el área

' Hoz, J. de.: 1993: «Las sociedades». El contenido de aquel trabajo y el de éste fueron presentados de forma más sucinta en de $\mathrm{Hoz}$ en prensa: «Paleohispanic Societies». Woolf, G.: 1994: en que dominaban las lenguas indoeuropeas ${ }^{2}$. Dadas las fuertes diferencias culturales que separan la Hispania indoeuropea de la no indoeuropea, es de esperar que los modos de usar la escritura en una y otra zona sean también diferentes, y que, a pesar de la considerable variedad que encontramos en el área no indoeuropea, ninguna de sus provincias epigráficas aparezca reproducida sin más en el ámbito "céltico", por utilizar una expresión tradicional y cómoda, aunque a mi modo de ver equivocada, que sirva para recoger a los distintos pueblos hispanoceltas y occidentales, de la misma forma que «ibérico» a menudo sirve para recoger a los distintos pueblos no indoeuropeos, ibéricos y no ibéricos.

2. De hecho la primera gran diferencia viene dada por la ausencia de alfabetización prerromana en gran parte de ese territorio ${ }^{3}$, que contrasta fuertemente con la casi total generalización de la escritura en el

"Power", cubre en parte el mismo campo pero sin ocuparse de los celtiberos y con información insuficiente, aunque en un contexto más ambicioso que no deja de tener interés a pesar de las dudas que suscitan sus conclusiones.

2 Con ello en realidad no queda completo el panorama de la Hispania antigua desde el punto de vista aqui adoptado, ya que es posible que la zona al $\mathrm{N}$. del Ebro, en el valle medio del río, sin ser indoeuropea no pertenezca tampoco propiamente al ámbito epigráfico ibérico. El problema es si realmente tenemos derecho a considerar ese territorio como alfabetizado en época prerromana.

" «Alfabetización» no es quizá una expresión del todo correcta para referirse a la difusión de escrituras que en el caso más típico, el semisilabario ibérico, sólo parcialmente son alfabéticas, pero podemos perdonar lo que se pierde en exactitud por lo que se gana en comodidad. En cuanto a uprerromano", en este contexto no implica cronologia, sino ascripción a una lengua hablada en Hispania ya antes de la llegada de los romanos. 
área no indoeuropea. Sólo los celtiberos y los lusitanos parecen habernos dejado inscripciones, pero creo que si valoramos adecuadamente los pocos textos de los segundos tenemos que relativizar, hasta casi negarla, la noción de epigrafia lusitana ${ }^{4}$. Las inscripciones lusitanas conservadas son sólo tres, $y$ todas al parecer del mismo caracter, inscripciones rupestres religiosas; faltan por completo tipos banales de epigrafe como los grafitos de propietario o las inscripciones sepulcrales. Por otra parte dos de las tres inscripciones conservadas se inician con una proclamación en latin de la identidad del o los autores de la redacción. Todo esto, unido a la poco definida ortografia utilizada, me hacen creer que en realidad nunca llegó a haber una auténtica epigrafia lusitana porque nunca existió una adaptación propiamente dicha del alfabeto latino al sistema fonológico de la lengua lusitana, que diese paso a una tradición de enseñanza y a la aparición de usos de la escritura propiamente lusitanos, en lengua lusitana transcrita de acuerdo con un sistema convencional propio. El contacto con el mundo romano sin embargo llevaria a ciertas comunidades lusitanas, en las que habia un número de individuos bilingües entre los que se daba un cierto grado de alfabetización en latín, a desarrollar una sensibilidad para los valores simbólicos de la escritura, y ello haria que en ciertas ocasiones solemnes requiriesen de algunos de esos individuos alfabetizados la redacción de un texto en la lengua local en que quedase constancia del acontecimiento, no por supuesto para que fuese leido por la masa de la población sino para enfatizar adecuadamente lo extraordinario de la ocasión. La transcripción en alfabeto latino del texto lusitano sería en cada caso un acontecimiento singular, que no crearía una tradición grafemática y que sólo contaría como antecedente con los hábitos existentes en la adaptación al latín de los nombres propios indigenas, geográficos, personales o de deidades, que servirian de guia a los poco avezados escribas en la resolución de la inhabitual tarea que les habia sido encomendada.

3. Nos quedamos pues reducidos a la epigrafia celtibérica como reflejo único de una sociedad hablante de una lengua indoeuropea que ha conocido y usado la escritura en la Hispania prerromana. El caso celtibérico, comparado con los que ya conocemos en la Península, es una vez más peculiar, diferente a los demás, pero a la vez, y por sorprendente que a primera vista pueda parecer, más similar al de

4 Hoz, de.: 1993: «Testimonios», pp. 364-365; en prensa: «Panorama». otras muchas sociedades mediterráneas que los estudiados en el artículo precedente. Por ello, antes de considerar la escritura celtibérica en términos más definidos, quisiera insistir sobre un modelo que ya he utilizado en otras ocasiones ${ }^{5}$ y que en mi opinión permite dar cuenta de la mayor parte de los, digamos «idiomas de escritura», o conjunto de prácticas y usos de la escritura que caracterizan a una sociedad dada, en el Mediterráneo antiguo en época prehelenistica, o, en el caso de Grecia, con anterioridad al desarrollo del modelo ateniense clásico".

Prescindiendo de casos especiales creo que puede afirmarse que la escritura en el mundo clásico y su periferia fue en general un conocimiento limitado a los miembros de las clases superiores y a los profesionales de ciertas actividades técnicas. $\mathrm{La}$ adopción de la escritura se produjo en la mayor parte de los casos respondiendo a incentivos prácticos y económicos, y su función más extendida, aunque no la más llamativa, fue práctica, y en buena medida privada, e incluia sobre todo la redacción de estados de cuentas diversos, rótulos, notas personales, breves mensajes e instrucciones de variados tipos, registros, actas y relaciones, y en general la anotación de operaciones económicas con el fin de conservar memoria de sus detalles durante el tiempo limitado en que podían considerarse todavia no concluidas. Si no conservamos muchos testimonios de esta clase de textos se debe al caracter perecedero de la mayor parte de los materiales utilizados como soporte, y a la actitud del mundo antiguo hacia este tipo de datos, muy distinta de la nuestra, que no los consideraba de interés fuera del periodo más o menos reducido de su utilización directa. Si el mundo ibérico proporciona un número de documentos de ese tipo desproporcionadamente alto ${ }^{7}$ en relación al total de los epigrafes conservados y en comparación con otras culturas es, en parte aunque no exclusivamente, por la utilización de un soporte, el plomo, menos perecedero que otros habituales en el Mediterráneo ${ }^{8}$.

En torno a estas funciones básicas se desarrollaron secundariamente otras varias, a menudo mucho más visibles en el testimonio arqueológico, y que desde el punto de vista de su valor simbólico para

\footnotetext{
5 Hoz, de.: en prensa: «Paleohispanic Societies»; 1995: «Escrituras"), pp. 61-62.

- A falta de un estudio general satisfactorio vid. Harris: 1989: Ancient Literacy.

"Hoz, de.: 1993: "La lengua»; 1994: "Griegos".

* Por supuesto en las culturas que utilizan el barro como soporte los documentos económicos o administrativos superan normalmente con mucho en número a cualquier otra clase de textos.
} 
las sociedades en cuestión pudieron llegar a ser más significativas que los usos prácticos mencionados. En la esfera privada estas funciones incluian textos conmemorativos, habitualmente portadores de una fuerte carga social como indicadores de status, tal como ocurria con las inscripciones honorarias, votivas o sepulcrales. En una situación intermedia entre los usos prácticos y los simbólicos se encontraban las inscripciones de propiedad, incluyendo los tipos más sencillos de inscripción votiva o sepulcral. Por otra parte existian, tanto en la esfera privada como en las restantes a las que nos referiremos, formas muy diversas de combinación de los aspectos prácticos y simbólicos.

Dentro de este modelo, que desde luego excluye algunas de las sociedades antiguas mejor conocidas, como la ateniense del clasicismo avanzado, no podemos esperar un uso amplio de la escritura para definir situaciones legales, para garantizar derechos o para facilitar el cumplimiento de las obligaciones, pero si encontramos un cierto papel de la escritura en la vida pública. Algunos aspectos de la legislación, algunas decisiones de la comunidad o acuerdos, por ejemplo tratados internacionales, que se consideraban de particular importancia o simplemente adecuados para ser objeto de una conmemoración material, se hacian públicos por escrito, y a la vez pudo desarrollarse en un cierto grado la elaboración de registros, $\mathrm{y}$ hasta iniciarse embrionariamente los archivos oficiales. Los aspectos simbólicos de afirmación de la comunidad y su ideología, o la ideología de los grupos dirigentes, fueron particularmente significativos en todos estos usos.

La religión se benefició también del uso de la escritura. Por una parte se desarrollaron en su esfera textos paralelos a los que hemos visto en la esfera pública, es por ejemplo el caso de las leyes sagradas, pero a la vez surgieron tipos especificos, como los textos oraculares o el registro de las tradiciones o de los hechos significativos de los santuarios. Por supuesto, como en el caso de la epigrafía pública, el factor ideológico era esencial en estos casos.

Por último la literatura podía existir en forma escrita o en forma oral, pero en cualquier caso desde este punto de vista el papel de la escritura resulta limitado dentro del modelo que estamos considerando. De hecho no creo que exista gran diferencia en la perspectiva de una historia social de la alfabetización entre una cultura que no conoce ninguna forma de literatura escrita y otra que depende básicamente de recursos orales para la creación, publicación y transmisión de la literatura, en una medida limitada se sirve de la escritura en la composición y transmisión, y no lo hace en absoluto en el proceso de publicación. Este es el tipo de relación entre escritura y literatura que asigno al modelo aquí propuesto.

Como en parte se ha visto en lo ya dicho, los motivos de la utilización de la escritura se mueven entre dos polos, el uso puramente práctico, escribir para poder recordar o para transmitir una comunicación a quien está ausente, y el puramente simbólico, el texto que no es necesario leer, que incluso quizá nadie o casi nadie puede leer, pero que por su sola presencia confiere prestigio o cualquier otro tipo de valor ideológico, sacralidad por ejemplo. Probablemente este último extremo no era muy frecuente en el mundo mediterráneo antiguo, a diferencia de Egipto" o Mesopotamia donde los muros de templos y palacios estaban adornados de multitud de textos que prácticamente nadie, ni los reyes cuyas glorias celebraban, podía comprender. Pero sí eran normales formas diversas de, digamos, mestizaje en que ambas funciones, la práctica y la simbólica, se combinaban en grados muy diversos. La cuestión, aparte su interés en si, que es muy grande, tiene un efecto útil para el estudioso actual, ya que las funciones simbólicas suelen ir unidas a variedades de soporte más o menos ricas $\mathrm{y}$, por ello, a menudo más o menos duraderas, que en sí mismas nos informan sobre ciertos aspectos del papel de la escritura en una sociedad dada y a la vez hacen posible que algunos textos lleguen hasta nosotros ${ }^{10}$.

En todo caso antes de ir más allá debo insistir en que este modelo, que no es sino eso, un modelo en el sentido weberiano, un útil de trabajo, tiene todavía un caracter inicial y rudimentario, pero que puede ya ayudarnos a evitar el error más habitual, y el de consecuencias más graves para la historia de las culturas y de las sociedades antiguas, que con excesiva frecuencia se ha producido desde que se inició el moderno interés por las cuestiones de historia de la escritura, y que puede asociarse de modo particular a las influyentes obras de J. Goody ". Es lo que

\footnotetext{
" Cuando hablo de mundo mediterráneo estoy utilizando un concepto que no sólo es geográfico sino también cultural, y en ese sentido no es contradictorio excluir de él al antiguo Egipto aunque de hecho poseyera una extensa costa mediterránea.

${ }_{10}$ En este sentido conviene diferenciar claramente uso de la escritura y expresión epigráfica, que es un concepto más reducido, aunque por falta de testimonios a menudo dependamos de nuestra información sobre la segunda para deducir el alcance del primero. En general en relación con el modelo propuesto podemos hablar de una expresión epigráfica arcaica, como precisamente en relación con los celtiberos ha subrallado F. Beltrán recientemente: 1993: "La epigrafia»; 1995: "La escritura». Cf. Hoz de, 1995: "Escrituras», 62 n. 34.

1) Un ejemplo característico en el campo especifico de la filologia clásica lo ofrece E. A. Havelock; vid. p. ej. Havelock: 1981 (=1978): «L'alfabetizzazione»
} 
B. Street ha llamado el «modelo autónomo» ${ }^{12}$, es decir el conjunto de ideas sobre la escritura teñidas de determinismo tecnológico que dan por supuesto que la mera posesión de ésta en una sociedad produce automáticamente una serie de desarrollos no sólo sociales sino incluso psicológicos, que quedarian particularmente a la vista en la evolución de la cultura griega desde la adopción del alfabeto hasta la aparición de Aristóteles. Frente a este modelo Street coloca el «ideológico», es decir el representado por teorías que ponen el énfasis en el modo en que los hábitos o modo de vida de las sociedades que adoptan la escritura condiciona el uso que hacen de ésta.

Está claro por lo dicho anteriormente que aqui propugnamos un "modelo ideológico", pero conviene advertir que a pesar de sus excesos el «modelo autónomo», o mejor dicho una versión suavizada de él que preferiria denominar «modelo tecnológico», no deja de tener validez.

Por otro lado lo que en este momento nos interesa es una cultura especifica, la celtibérica, y por lo tanto más que perfeccionar el modelo como tal debemos utilizarlo como instrumento de comprensión. Desde este punto de vista es obvio que una de sus limitaciones mayores es su escasa consideración del punto de vista cuantitativo, ya que acomoda por igual culturas con muy distinto volumen de producción escrita, pero a pesar de todo creo que es útil para comprender mejor cualquiera de ellas considerar como un grupo todas las sociedades que han desarrollado las funciones de la escritura arriba descritas, es decir la mayor parte de las griegas e itálicas pre-helenísticas, y separarlas de otras que muestran diferencias cualitativas unidas normalmente a otras cuantitativas que pueden llegar a ser enormes. Un evidente punto de ruptura lo representan por ejemplo la nueva conciencia de las potencialidades civicas de la escritura o el nacimiento de géneros literarios técnicos dependientes de ella que aparecen contemporáneamente en la Atenas clásica.

4. El uso celtibérico de la escritura responde, según creo, al modelo propuesto. Los celtíberos aprendieron a escribir de los iberos - aunque vid. infra-, y la epigrafia, por ahora relativamente escasa, que de ellos nos ha quedado, muestra textos de caracter público y privado, aunque no documentos económicos privados de caracter práctico, lo que puede tal vez atribuirse a su posible existencia en soportes perecederos; no hay que olvidar sin embargo que a

12 Street: 1984: Literacy, citado en Thomas: 1989: Oral Tradition, pp. 24-25. la vez que recibieron de los iberos la escritura podrian haber recibido el uso de las láminas de plomo como material de escritura, y sin embargo no tenemos plomos celtibéricos ${ }^{13}$. En todo caso hay obvias diferencias entre los usos epigráficos de ambas culturas, lo que dada la dependencia histórica de la una con respecto de la otra apunta a un distinto contexto social de los usos escriturarios. Sobre la cuestión volveré más adelante.

Concretamente la epigrafía celtibérica conocida incluye inscripciones de propiedad y sepulcrales, leyendas monetales, un par de textos oficiales sobre bronce - tal vez tres $-{ }^{14}$, inscripciones votivas aunque casi exclusivamente en escritura latina, marcas de construcción, un documento privado sobre bronce de función desconocida, y un buen número de tesserae hospitales ${ }^{15}$. Cada uno de estos tipos plantea sus propios problemas, pero podemos agruparlos en categorías mayores que facilitan su comprensión, en especial si contraponemos textos privados a textos públicos y textos de exhibición a textos internos.

5. Los grafitos cerámicos de propiedad pertenecen a un tipo relativamente banal, bien conocido en las más diversas culturas ${ }^{16}$. Albalate ${ }^{17}$ y Graccurris ${ }^{1 \mathrm{x}}$ han proporcionado un grafito cada una, y Caminreal dos ${ }^{19}$, mientras que sendos grupos proce-

is Recientemente se ha publicado uno - Fletcher, D. \& Pérez Vilatela, L.: 1994: «Dos», pp. 361-364 , pero de procedencia desconocida y anómalo no sólo por el hecho de tratarse de un plomo sino porque el texto de una de sus caras se explica mejor como ibérico. La situación cada dia menos clara de los numerosos documentos que están entrando en colecciones particulares sin pasar por un análisis técnico adecuado hace necesario, según creo, prescindir de momento en estudios generales de todos aquellos que resulten anómalos.

${ }_{14} \mathrm{El}$ último bronce aparecido en Botorrita, al parecer mero fragmento, se conoce sólo por la prensa. y no será considerado aqui.

is Untermann: 1983: «Keltiberer»; de Hoz: 1986: «Epigrafia celtibérica".

it En las referencias utilizo la numeración que en su dia tendrán las inscripciones celtibéricas en MLH, y que ya ha sido adelantada parcialmente por J. Untermann en algunas publicaciones - 1990: "Comentarios", passsim; 1994: "Anotaciones", 388; 1995: "Epigrafia», especialmente 208, mapa 2-. y una segunda referencia a diversas publicaciones recogidas en la bibliografia, que permita identificar el texto por el momento. Por lo tanto se entiende que las siglas formadas por $\mathrm{K}+$ números van implicitamente precedidas de $\mathrm{MLH}$; de citar inscripciones no celtibéricas utilizaré la referencia completa. Agradezco a J. Untermann el que me haya facilitado lo que en su dia será el corpus celtibérico de MLH en su estado actual de elaboración.

i7 K. 2.1 = Sup. 29.

1* Hernández Vera, J. A. \& Núñez Marcen J.: 1989: «Un nuevon, probablemente no celtibérico.

14 K.5 (antes K.30), 1-2 = Vicente, J. D., M*. P. Punter, C. Escriche \& A. I. Herce: 1993: «Las inscripciones», pp. 757-760. 
den de Numancia y Botorrita ${ }^{20}$. Finalmente un par de grafitos del valle del Ebro que se prestan a discusión me parecen ibéricos. ${ }^{21}$ Ninguno de estos grafitos está en alfabeto latino 22 .

Los grafitos numantinos son de dos clases, letras sueltas o abreviaturas y textos propiamente di$\operatorname{chos}^{23}$. Los textos figuran en recipientes de tipos diversos que hasta hace poco carecian de un estudio ceramológico adecuado, pero ahora Arlegui ha podido confirmar la fecha avanzada de los textos ${ }^{24}$, en el siglo i a.C. e incluso algunos ya dentro del siglo 1 d.C.

En cuanto a la interpretación de los textos, en un trabajo anterior he intentado demostrar que podria tratarse de indicaciones de propiedad no relativas a un individuo sino a una familia ${ }^{25}$, y los posteriores hallazgos de Caminreal parecen confirmar la idea

Los grafitos de Botorrita son en general meras marcas o abreviaturas sobre cerámica campaniense en su mayor parte; sólo dos de ellos presentan un interés mayor, un fragmento de campaniense B con un grafito lamentablemente incompleto pero que tenia sin duda cierta longitud ${ }^{20}$, y una patera campaniense, de la que los editores no dan descripción más precisa, en la que se grabó lo que sin duda, aunque no deja de plantear ciertas dificultades, es una fórmula onomástica completa ${ }^{27}$.

${ }^{20}$ K.9.2-8 = Sup. 88-93 y cf. Paulsen, R.:1931: Numantia lam. 34: K.1.4-15 ; Beltrán Martinez: 1983: «Epigrafia», pp. 106107; Beltrán Martinez, A. \& Fletcher, D.: 1991: “Dos inscripciones», pp. 31-33.

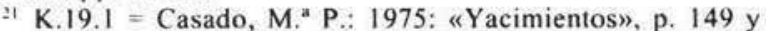
fig. 5.4.; K.28.1 = Beltrán, M.: 1977: «Novedades», pp. 188193. Otro grafito, casi seguramente falso, está grabado sobre un vaso griego del siglo IV que se conserva en Catana y debió aparecer en los alrededores: MLH XLIla.

22 Si están en alfabeto latino sin embargo los grafitos de Ablonios, en Capote - Berrocal, L.: 1989: «El asentamiento», pp. 259-288: 1992: Los pueblos, pp. 115 y 362 - pero pertenecen a un mundo distinto del celtibérico y del lusitano, $y$ aunque indoeuropeos están aún demasiado aislados como para tomarlos en consideración en este estudio

${ }^{23}$ F. Wattenberg: 1963: Las cerámicas, incluye en su inventario las siguientes piezas con grafito: números $367,567,593,730$, $731,735,747,779,867,962,981,1100,1191$ (=401) y 1202, pero excepto en dos casos se trata de marcas o de signos sueltos. En cuanto a Romero, F.: 1976: Las cerámicas, no se comenta ninguna pieza de las que aqui nos interesan. Paulsen, R.: 1931: Numantia, recoge los grafitos en la lámina 34 - comentario en página 268- Pero el estudio más detallado de los signos y marcas es Arlegui, M.: 1992: "Las cerámicas», pp. 480-484, n. 10-29 y $41-43$ de lam. 2-4, que recoge también los signos sobre terra sigillata estudiados en Romero, M." V".: 1985: Numancia.

24 Arlegui, M.: 1992: "Las cerámicas", en especial pp. 476479 para los textos propiamente dichos.

${ }_{25}$ Hoz, J. de.: 1986: "La epigrafia», pp. 58-59, 96.

${ }^{26}$ K.1.4; Beltrán Martinez: 1983: «Epigrafia», p. 106.

27 K.1.5; Beltrán Martínez, A. \& Fletcher, D.: 1991: «Dos inscripciones", pp. 31-33.
En relación con los grafitos cerámicos conviene mencionar, aunque sólo sea de pasada, las marcas sobre pesas de telar ${ }^{2 x}$, que en algún caso son claramente abreviatura de un nombre, y un caso aislado de inscripción sobre una fusayola, procedente de Monreal Z (K.7.1 = Sup. 83).

Todavia conviene añadir aqui, aunque no se trate de cerámica, otras inscripciones sobre un objeto de uso. Un fragmento de un gran plato de bronce, aparecido en Gruissan (K.17.1 = MLH II B.3.1), en lo que fue el el puerto antiguo de Narbona, y otro recipiente, en este caso de plata ${ }^{29}$, que fue hallado al parecer en Monsanto (Castelo Branco).

Por último el corpus de inscripciones celtibéricas sobre vajilla incluye dos páteras con escritura latina, procedentes de Tiermes (K.11.1-2) y hoy perdidas por lo que dependemos de la lectura de Fita sobre el original y de Hübner sobre fotografias; el texto mayor plantea varias dificultades de interpretación ${ }^{30}, y$ no estoy seguro de que la interpretación más banal como inscripción de propietario sea correcta. Surge la tentación de interpretar ambas páteras como ofrendas procedentes de un mismo lugar sagrado ${ }^{31}$, realizadas por distintas personas, mientras que dos inscripciones de propiedad celtibéricas en objetos iguales y con procedencia común pero relativas a dos distintos propietarios resultan poco verosímiles.

Finalmente entre las inscripciones cuyo objeto es definir o atribuir su soporte a algo o alguien podríamos incluir las marcas sobre tambores de columnas de Botorrita ${ }^{32}$, que probablemente tenian por finalidad la determinación de su orden una vez desmontados.

Como se ve el número de grafitos, o más generalmente, de inscripciones de propiedad celtibéricas, no es muy elevado, pero antes de sacar conclusiones sobre la mayor o menor familiaridad de los celtíberos con la escritura convendrá matizar algunos extremos, en especial que los hallazgos son re-

2x K.20.1; Fatás, G.: 1967: «La colección"; Martín Bueno, A.: 1968: «Pesas».

${ }^{29}$ K.0.1; Gómes, M. Varela \& Beirâo, C. de Mello: 1988: "O tesouro».

30 Gorrochategui: 1990: «Consideraciones», pp. 304-311 con la bibliografia anterior, a veces excesivamente simplista. Añadir Garcia y Bellido, A. \& Garcia-Bellido, M." P.: 1993: Album, lám. 181.

"Junto con otras dos, con inscripción latina, que se conservan en la Hispanic Society de Nueva York. Según I. Calvo, RABM 29, 1913, p. 383 , citado en Garcia y Bellido, A.: 1966: «Las Trullae», 119, en la llamada "Tierra de las tazas" por haberse hallado en ella los recipientes, se veian restos de un gran edificio, que seria un templo.

32 Beltrán Martínez: 1983: «Epigrafia», pp. 103-106. 
lativamente abundantes en los casi únicos yacimientos de habitación, Botorrita y Numancia, que han sido excavados en una cierta amplitud.

6. Las lápidas sepulcrales celtibéricas entroncan por una parte con la tradición ibérica y por otra anuncian las estelas de época romana de la zona e incluso los tipos rústicos, sobre peñascos, que en época imperial encontraremos en algunas zonas de la Hispania indoeuropea ${ }^{33}$. Su número es todavia hoy muy escaso, y curiosamente el ejemplar más interesante no procede de Celtiberia, sino de Ibiza ${ }^{34}$. Las restantes inscripciones sepulcrales son menos significativas. La influencia ibérica, del tipo de estelas del Bajo Aragón, se manifiesta en un par de estelas con decoración figurada procedentes de Peñalba de Castro, Clunia (K.13.1 = Sup. 95; K.13.2 = MLI XXXVI) ${ }^{35}$; ambas muestran la escritura redundante propia de la influencia latina. Los fragmentos de El Pedregal (Guadalajara), rudos, de dudosa lectura y uno al parecer perdido, no es seguro que sean sepulcrales $^{36}$. Si parecen sepulcrales, por el contrario, otras piedras rústicas, procedentes de Langa de Duero (K.12.1 = Sup. 96), Uxama (K.23.1), Torrellas (K.8.1 $=$ MLH XIV ${ }^{37}$, de dudosa interpretación, y Trébago (So.) (K.22.1) ${ }^{38}$, la lápida celtibérica más recientemente aparecida.

De nuevo tenemos que señalar que la epigrafía sepulcral celtibérica es numéricamente muy pobre, y de nuevo tenemos que matizar la afirmación. En este caso sin embargo no hay motivos para achacar el problema en parte a la ausencia de exploración arqueológica ya que las necrópolis celtibéricas si han sido objeto de la continuada atención de los arqueólogos ${ }^{30}$.

7. La epigrafia rupestre celtibérica por ahora se reduce a sólo dos puntos, la cueva de San Garcia $\mathrm{BU}$ con una inscripción en caracteres ibéricos de

${ }^{33}$ En general Marco, F.: 1978: Las estelas; Abásolo, J. A. \& Marco, F.: 1995: "Tipologia», pp. 328, 331, 335-337. La continuidad de la tradición ibérica no sólo se manifiesta en la noción misma de estela inscrita, sino tambièn en temas figurados, como el del jinete o el de los buitres que devoran un cadáver (Marco, F.: 1976: "Nuevas»), y en los objetos simbólicos - rodelas entre los celtiberos, lanzas y manos entre los iberos.

${ }^{34}$ K.16.1 = Sup. 120; Untermann: 1967: «Endung des Genitiv", pp. 283-284.

${ }^{35}$ Al parecer existe otra piedra celtibérica inscrita procedente de Clunia, aủn inédita.

36 MLH XXXVIla (K.4.1-2) y b. El fragmento a se conserva actualmente en el MAN de Madrid.

37 Untermann: 1990: "Comentarios», pp. 355-356.

38 Albertos, M." L. \& Romero, F.: 1981; "Una estela»; Untermann: 1990: "Comentarios», p. 354.

30 En general vid. II Simposium: 1990. lectura todavia insegura "t" pero que por su situación muy occidental dificilmente puede ser otra cosa que celtibérica, y el importante conjunto de Peñalba de Villastar, cuya epigrafia es básicamente latina o celtibérica en alfabeto latino.

El conjunto gráfico de Peñalba de Villastar está constituido por casi tres $\mathrm{kms}$. de cantera de caliza clara, expuesta a Norte, Levante y Mediodia, en la parte superior del monte de Peñalba, al que da nombre, en la cuenca alta del Turia, y dominando el acceso al estrecho de Villel que controla la ruta desde el Mediterráneo al interior siguiendo el curso del mencionado río. Fue descubierto por Cabré y publicado en 1910, junto con lo que es todavía la mejor descripción del lugar ${ }^{+1}$. En la cantera se hallan cazoletas, grabados geométricos, figuras humanas o tal vez divinas y animales, a veces aisladas, a veces formando auténticas escenas, $y$ un considerable número de inscripciones, no sólo celtibéricas en alfabeto latino sino también ibéricas de dudosa adscripción y varias latinas al parecer de distintas épocas, entre ellas una conocida cita virgiliana en el mismo tipo de letra que alguna de las celtibéricas.

Falta todavía un estudio sistemático, detenido y con recursos suficientes del lugar pero no cabe duda de su caracter religioso; en parte tiene características comunes con los abrigos ibéricos ${ }^{42}$, pero se distingue de ellos por su envergadura incomparablemente superior. Cabré lo consideró un santuario de frontera, en el que coincidian gentes de etnias distintas $^{43}$, y la idea es atractiva, pero tampoco hay que perder de vista su posición estratégica, arriba mencionada, que podría explicar al menos una parte de los grabados e inscripciones como paralelos en función a los ibéricos de la Cerdaña. En todo caso la magnitud del conjunto obliga a pensar no en un simple lugar de paso sino en un auténtico santuario, visitado exprofeso por gentes diversas con una cierta frecuencia; la hipótesis de Untermann, según la cual los textos que nos interesan se deberian a peregrinaciones realizadas hacia el cambio de era, y que no durarian más allá de una generación ${ }^{44}$, resulta muy plausible en lo que se refiere a la epigrafía celtibérica pero no debe ser necesariamente extendida a la vida religiosa del lugar, que sin duda fue mucho más larga.

\footnotetext{
40 K.24.1 = Albertos: 1986: "Inscripción... de San Garcia».

4 Cabré: 1910: "Montaña escrita».

42 Pérez Ballester, J.: 1992: "El abrigo»; Cardito, L. M. ${ }^{\text {, Ga- }}$ laz, M. \& Moneva, M.* D.: 1993: "Inscripciones»; Hoz, de,: en prensa: «Panorama».

${ }^{43}$ Op. cit., pp. 260-261

44 Untermann: 1995: «Epigrafia», pp. 200-201.
} 
Por su parte la epigrafia celtibérica del lugar se desglosa en veinte epígrafes - dieciseis en MLH, K. 3.3-18- ${ }^{45}$, algunos de ellos en realidad divisibles en más de una inscripción, aunque a veces no sea fácil llegar a una conclusión definitiva, lo que, unido a algunas dudas sobre el caracter celtibérico o latino del texto (en especial $\mathrm{n}^{\circ} 14, \mathrm{y}$ también $13 \mathrm{y}$ las dos primeras líneas de $2=K .3 .18)^{\text {th }}$, nos deja con un máximo provisional de 25 inscripciones, de las que tres están perdidas tras haber sido arrancadas de la roca $^{\text {t7 }}$, quince se encuentran en el Museo de Barcelona integradas en once piezas ${ }^{48}$, y el resto debieran hallarse en la cantera de Peñalba, donde por otra parte no sería de extrañar, dada la ausencia de una exploración lo suficientemente larga y con infraestructura adecuada, que se puedan detectar otras inéditas.

Para varias de estas inscripciones no existe una lectura adecuada por razones diversas, en algunos casos porque el desgaste de la roca lo hace imposible. De las que pueden ser leídas con garantia, al menos en una parte significativa de su texto, y dejando de momento a un lado la inscripción mayor, destaca la presencia de NNP (nombres de persona), que incluso parecen agotar en algunos casos la totalidad del texto $\left(\mathrm{n}^{\circ} 2,10-3\right)$, con o sin mención de grupo familiar. En ocasiones encontramos términos que pueden pertenecer al léxico común, como el posible título VERAMOS $\left(n^{\circ} 5\right.$ y 6 ).

Un caso especial es el de TVROS, atestiguado (con la variante TVRROS) en seis ocasiones $\left(n^{\circ} 6\right.$, $7 \mathrm{a}, 7 \mathrm{~b}, 8,9$, y K.3.17) ${ }^{49}$. Puesto que el NP Turos y

${ }^{45}$ K.3.1-2 (Sup. 80-1) están en escritura ibérica, pero K.3.1(c), 17 a de Gómez Moreno, podria estar en escritura latina. El número de veinte epigrafes es la suma de los dieciocho incluidos en $n^{\circ} 1-17$ de Gómez Moreno - el $n^{\circ} 7$ corresponde claramente a dos epigrafes - más dos publicados en 1977 por J. Untermann (vid, n. siguiente), ya que no me parece posible que uno de éstos coincida con $6+11$ de Gómez Moreno.

46 Utilizo la numeración de Gómez Moreno en 1949, «Suplementon, pp. 326-330, seguida de la de MLH K.3, que es la referencia de Peñalba. De las inscripciones publicadas por J. Untermann como "textos inéditos I y I1" en 1977: "En torno", pp. $16-20$, la primera es K.3.17. la segunda parece haber sido excluida de MLH; de esa misma publicación proceden las determinaciones por medio de letras minúsculas de algunos de los números de Gómez Moreno.

$47 \mathrm{~N}^{0} 6,13$ y 15.

${ }^{4 x} \mathrm{~N}^{\circ} \mid$ (K.3.3), 3-5 (4-6), 7 y 8 (8-11, posiblemente dos inscripciones cada una, vid. Untermann, op. cit., 7-10), 9 y 10 (12-3), 12 (14) y 17 (1 y 15-6; posiblemente contiene tres inscripciones, vid. Untermann, op. cit., 13-5, aunque repartidas en dos piezas).

49 De aceptar la lectura de Tovar. TVRROS en lugar de TVLLOS, en el n¹2 (Tovar: 1949: Estudios, 32; 1959: "Inscripciones celtibéricas", 358-9), o TVRRO al final del mismo $n^{\circ}$ (Untermann: 1977: "En torno», pp. 11-13), serian siete, pero me parece prácticamente segura la lectura TULLOS, y no estoy seguro de que se pueda obtener nada más que alguna letra suelta del final del texto. sus derivados era frecuente en la Hispania antigua, e incluso en otras zonas de Europa ${ }^{51}$, podría pensarse en una simple coincidencia entre diversos devotos, pero algunos datos plantean dificultades, por lo que no puede desecharse la propuesta de Untermann, que ve en turos un posible teónimo o término de culto como votum o donum ${ }^{\text {st. }}$.

La inscripción mayor de Peñalba es sin duda uno de los textos más importantes del mundo hispánico prerromano. Sobre su lectura existen escasas dudas, y hay muchas cosas que resultan evidentes desde el primer momento, en especial la forma verbal SISTAT, correspondiente a una raiz bien conocida en las lenguas indoeuropeas y con buenos paralelos en usos sacrales, de los que se puede citar por tratarse de un caso muy vulgarizado el de la inscripción votiva de Satricum, pero sobre todo lo más significativo es la presencia de LUGUEI, sin duda dativo del teónimo céltico bien conocido. Pero a pesar de algunos progresos recientes, y a pesar de que la inscripción ha sido estudiada repetidas veces ${ }^{52}$, sigue planteando graves problemas de interpretación, aunque nadie parece dudar de que se trata de una inscripción de caracter religioso, votiva o en la que se conmemora alguna acción sacral.

8. Epigrafia monetal ${ }^{53}$. Una parte importante de las monedas correspondientes a cecas que las fuentes históricas atribuyen a los celtiberos presentan en sus leyendas rasgos gramaticales bien definidos que se dejan interpretar en el marco de la lingüística indoeuropea ${ }^{54}$. Esos rasgos reaparecen en otras cecas no identificadas por las fuentes, a menudo asociadas a rasgos propiamente numismáticos visibles también en las monedas celtibéricas, lo que nos permite incluir en un mismo ámbito lingüístico e histórico unas y otras cecas. Datos secundarios utilizables como indicios de localización geográfica, tales como distribución de hallazgos, valores emitidos, clases de metal acuñado, o peculiaridades gráficas

\footnotetext{
50 Albertos: 1966: Onomástica, pp. 236-240; Abascal, J. M.: 1994: Los nombres, pp. 533-535.

st Untermann: 1977: «En torno", 7. Cf. ya Cabré: 1910: «Montaña escrita», p. 278.

52 Tovar: 1956: «La inscripción»; Schwerteck, H.: 1979: «Zur Deutung»; Ködderitzsch, R.: 1985: «Die große»; Eska: 1990: "Syntactic»; Villar: 1991: «Le locatif»; Meid: 1994: "Die "große»; 1994: Celtiberian, p. 30-37; Hoz, de,: en prensa: «Panorama».

53 En este apartado las referencias con A y numeral reenvian a MLH I.

34 Tovar, A.: 1946: «Las inscripciones», pp. 29 ss., y previamente Caro Baroja, J.: 1942-1943: "Observaciones», pp. 32-36; vid. ahora Villar: 1995: Estudios ; en prensa: «Nueva interpretación».
} 
de las leyendas, confirman nuestras conclusiones $\$ 5$. Asi se definen como celtibéricas las cecas A.47-A.59 y A.61-A.93 del corpus de Untermann, es decir, cuarenta y seis cecas, a las que hay que añadir con seguridad una procedente del desdoblamiento de A.75 en que Untermann ha unido dos cecas distintas, y quizá alguna de las de su grupo IVa (A.36 - A.46) s6 $^{\text {. }}$.

El propio Untermann agrupa las cecas celtibéricas en una serie de regiones, la del Ebro, la de Celtiberia septentrional y la del Jalón y el Henares ${ }^{57}$. Un importante descubrimiento reciente obliga sin embargo a replantear algunos aspectos de la geografia numismática celtibérica. La ceca A.91, tamiusia, situada por Untermann por razones tipológicas «im mittleren Keltiberien", no lejos de Sigüenza (A.77), Segeda (A.78), y las cecas no localizadas A.85 okalakom, A. 87 roturkom, y A.88 samala, ha resultado corresponder al castro de Villasviejas de Tamuja, Botija CC, donde parecen ser abundantes los hallazgos de estas raras monedas ${ }^{58}$, y que conserva el topónimo celtibérico minimamente transformado en el nombre del riachuelo que corre a su pie, y que pudo originalmente haber dado nombre al asentamiento celtibérico ${ }^{54}$. La nueva identificación de la ceca A.91, que está siendo generalmente aceptada ${ }^{\circ 0}$, abre perspectivas insospechadas no hace mucho sobre la epigrafia celtibérica, ya que parece que, aparte los movimientos más o menos antiguos de gentes de la Meseta hacia varias zonas del S.O. de los que existen indicios arqueológicos e historiográficos ${ }^{61}$, parece que hay que contar también en fecha avanzada con desplazamientos de celtiberos en el sentido más estricto y en posesión ya de su escritura, por lo que hay que tomar en consideración un territorio mucho más amplio en los intentos de identificación de las muchas cecas celtibéricas que carecen de ella,

ss Untermann, J.; 1964: "Zur Gruppierung»; 1984: Die Münzprägungen». También aqui se podria mencionar el precedente de J. Caro Baroja siguiendo las huellas de los numismatas de la generación anterior.

st MLH I 1, pp. 56-61, y el indice de cecas. Información sobre los distintos inventarios de leyendas monetales celtibéricas debidos a distintos autores, y que podemos considerar superados, en de Hoz: 1986: "La epigrafia», pp. 63-64.

${ }^{37}$ MLH 1 1, en especial p. 61. Agrupación ligeramente diferente en Villaronga, L.: 1979: Numismática, pp. 142-190 y 194. 206, y cf. también 1994: Corpus, pp. 213, 230-47, 268-300 y las cecas que el A. incluye en territorio vascón en términos geográficos pero sin negar su adscripción lingüistica a los celtiberos, como Turiaso, pp. 262-267.

98 Sánchez Abal, J. L., \& S. García Jiménez: 1988: «La ceca».

39 Villar: 1995: "El hidrónimo".

to Garcia-Bellido: 1995, pp. 267-271. No la acepta sin embargo Villaronga: 1990: "El hallazgo"; 1994: Corpus, p. 247.

"Hoz, de.: en prensa: "La inscripción»; en prensa: «Areas"; en prensa: "Tartesio». y porque cabe incluso la posibilidad de que aparezcan en Extremadura inscripciones celtibéricas de otros tipos ${ }^{62}$.

La cronologia de la moneda celtibérica dista de estar clara, y lo mismo ocurre con el problema, intimamente relacionado, de su interpretación históri$\mathrm{ca}^{\text {n3 }}$. En todo caso a la vista de la bibliografia de los últimos años ${ }^{\circ 4}$, que viene a coincidir con ideas tradicionales de numismatas como Gómez Moreno o Amorós, creo que la hipótesis con mucho más plausible situaria el nacimiento de la moneda celtibérica, como consecuencia más o menos directa de las imposiciones fiscales de Roma, en los años de organización de la conquista que tienen su centro en la presencia en Hispania de Graco (180-178); es seguro en todo caso que la moneda celtibérica existía ya durante la guerra numantina. Por supuesto no todas las cecas acunaron desde el primer momento, $y$ algunas debieron empezar a emitir en fecha muy avanzada, próximo ya el s. I. Otro resultado significativo de la bibliografia reciente ha sido la jerarquización de las cecas; sólo algunas en efecto, cuyo papel administrativo fue al parecer central en un determinado territorio, acuñan plata, mientras que otras subordinadas se limitan al bronce ${ }^{b 5}$. Quedan sin embargo muchos detalles por entender desde este punto de vista, por ejemplo en qué medida esa jerarquia tiene antecedentes en época prerromana, y desde el punto de vista de este estudio en qué medida la acuñación de bronce, aunque sin duda una consecuenciaa de la de plata, respondió a circunstan-

\footnotetext{
62 En Villasviejas ha aparecido, aparte algunas marcas en cerámica, un interesante óstracon en escritura meridional-Hernández Hernández, F.: 1985: "Nuevos»; Hernảndez Hernández. F., Rodriguez, M.* D. \& Sánchez, M." A.: 1989: Excavaciones, pero parece que hay que atribuirlo a los predecesores de los celtiberos en la zona. Por otra parte hay noticias sobre la posible procedencia extremaña de alguna de las téseras de origen desconocido recientemente publicadas, y existe alguna importante pieza epigráfica celtibérica inédita que procedería de esa zona. Agradezco varias noticias en este sentido a M. Almagro-Gorbea, A. M." Martin y J. Pellicer.

6) Breve estado de la cuestión, superado ya, en Hoz, de.: 1986; "La epigrafia", pp. 65-66.

is Garcia-Bellido, M** P.: 1993: "Origen», pp. 107-111; en prensa: "Los ámbitos». Beltrán Lloris, F.: 1986: "Sobre la función"; 1993: "La epigrafian, p. 253; 1995: "La escritura», pp. 174-175. Beltrán sin embargo es partidario de una cronologia baja que no comparto, y parece aceptar una interpretación de la moneda celtibérica como fenómeno fronterizo que en mi opinión no sólo es errónea sino que contradice sus propias ideas sobre la función de esa moneda; mejor que de frontera podriamos hablar de dominio sin romanización, aunque por supuesto el dominio implica ya un proceso incipiente que en su dia puede convertirse en romanización.

"s Burillo, F.: 1983-1984: "Sobre la situación»; 1986: "So-
} bre el territorion. 
cias internas de las ciudades celtibéricas y constituye un fenómeno más autóctono, y por lo tanto más significativo como indice de familiaridad con la escritura, que la de plata, cuyo interés desde este último punto de vista es limitado, dada la fuerte dependencia de la administración romana que según todos los indicios presupone. Por otro lado es de suponer que la moneda de bronce "corriera» mucho más que la de plata, y por lo tanto que jugase un papel más significativo en el fenómeno, difícil de valorar pero sin duda importante, de familiarizar a amplios grupos con los signos escritos.

En cuanto a las leyendas propiamente dichas, se trata en su totalidad de topónimos o adjetivos derivados de topónimos y de signos sueltos o abreviaturas de dificil interpretación. Los nombres, por el contrario, se dejan interpretar con facilidad y se reducen a un pequeño número de formas gramaticales, cuya identificación tradicional tal vez sea necesario revisar en ciertos casos ${ }^{66}$, sin que eso afecte a los problemas de definición lingüistica y adscripción a ciudades que son los que en este momento nos interesan.

9. Las téseras constituyen un rasgo distintivo del uso celtibérico de la escritura, nacido de la convergencia de un modelo clásico y de un aspecto importante de las prácticas sociales celtibéricas. Se trata de un conjunto de documentos de extraordinario interés en estrecha relación con otros dos grupos, téseras celtibéricas en escritura latina y téseras propiamente latinas ${ }^{67}$. Dentro del grupo estrictamente celtibérico contamos con documentos de cierta longitud, la tésera de Luzaga y la recientemente publicada de El Burgo de Osma (So.), y breves, de Monreal, Sasamón, Cabeza del Griego, Palenzuela, París, La Mesa de Belorado, La Custodia y de procedencia ignorada. A ellas debe añadirse la planchuela de Numancia, que creo no admite otra interpretación.

Excepto ésta y la tésera de Luzaga y algunas que

th $\mathrm{La}$ interpretación tradicional puede verse en $\mathrm{MLH} \mathrm{I,} 84$. 88; las nuevas propuestas en Villar: 1995: Estudios; en prensa: «Nueva interpretación».

67 Tovar: 1948: «El bronce»; Lejeune: 1955: Celriberica, pp. 65-113: Untermann: 1990: "Comentarios", pp. 357-369. Lista de los documentos latinos mayores en da Silva, A. C. F.: 1983: «As tesserae», pp. 9-26, con mapa de distribución y cuadro sinóptico; los documentos menores en Garcia y Bellido: 1966: "Tessera», pp. 162-163, con mapa en la p. 166, a los que hay que añadir Garcia Merino, C.: 1980: «Una tessera», y Burillo, F.: 1978: "Una nueva", recogida por el mismo autor en 1980: El valle, pp. 163-164 y lám. 40. Generalidades sobre las téseras latinas de Hispania en Curchin: 1994: "Juridical», pp. 92-99; Etienne et alii: 1987: "La tessera». presentan una complicada disposición volumétrica, las restantes son figurativas; entre éstas hay que distinguir dos tipos, figurillas de bronce separadas en dos mitades simétricas que muestran por lo tanto una cara en bulto redondo y otra plana donde se graba el texto, y simples siluetas recortadas, planas por ambos lados. Me inclino a ver en este segundo tipo una variante digamos «pobre» del primero, aunque todavia más humilde es el tipo representado por la planchuela de Numancia. Lo representado en las téseras figurativas es un animal en siete casos, y unas manos unidas en uno. Como es sabido, estas figuras tenían un valor simbólico y formaban parte integrante del contenido identificador de las téseras, al igual que el texto. En cada caso existian dos documentos de forma idéntica, superponibles uno sobre otro, que estaban en posesión de cada una de las partes implicadas en el pacto del que la tésera es symbolon, y de hecho éste es el nombre original de la tésera en Grecia, que fue donde se inició la institución ${ }^{6 x}$.

Las téseras celtibéricas de fecha ya romana según todos los indicios, en parte en escritura latina y con idéntica distribución a las téseras estrictamente latinas más antiguas, deben representar la adopción de un uso clásico llegado con los romanos, que a su vez lo habian tomado de los griegos. Esta imitación, sin embargo, se restringe a la expresión epigráfica de unos usos sociales, no a estos últimos, que sin duda existian ya entre los celtiberos ${ }^{69}$.

En cuanto a la interpretación concreta de las téseras celtibéricas, como ya he dicho, existe un tipo breve y un tipo más desarrollado; el tipo breve, más sencillo, permite aproximarse a la interpretación del más desarrollado en sus distintas variantes, y ambos se aclaran en parte por el recurso a las téseras latinas en una aplicación particularmente legítima del mal llamado método «de los cuasi bilingües».

Las téseras celtibéricas breves pueden ser subdivididas a su vez en dos grupos, de acuerdo con su contenido. Enumero en primer lugar las que corresponden al más numeroso: K.0.3 = Sup. 85 , K.0.4 = Sup. 87, K. $0.5=$ Sup. 86, K.7.2 = Sup. 82 , que ya

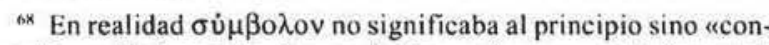
traseña", sólo luego llegó a equivaler a "signo" y posteriormente aún a "pacto». Ver Gauthier, P.: 1972: SYMBOLA, pp. 62-104.

ov Vid. igualmente Beltrán Lloris, F.: 1993; "La epigrafia", p. 263 ; 1995: "La escritura", p. 180. No veo las bases que permitirian atribuir también a la influencia romana el aspecto institucional de la hospitalidad; $c f$. Dopico, M. ${ }^{a}$ D.: 1989: «El hospitium». 
estudié en $1986^{\circ 1}$, a las que hay que añadir ahora K.25.1 (Palenzuela P) ${ }^{71}$. El elemento común a todas estas téseras es la mención de una comunidad politica, y puede ser ejemplificado con la más compleja:

\section{K.0.5: libiaka / kortika : kar}

Todas ellas llevan una indicación que las define como «(tésera) de (la ciudad) X». En algunos casos, como el citado, además del adjetivo encontramos una indicación añadida que implica un texto más explícito, «tésera (o similar) de (la ciudad) X». Una confirmación de esta lectura la tenemos en la tésera latina de Las Merchanas cuyas dos primeras lineas se leen tes(s)era/Caurie(n)sis ; el adjetivo latino cauriensis es a Caurium (Ptol. II 56) como seria el celtibérico *kaurioka.

El segundo grupo de téseras celtibéricas breves se caracteriza por contener simplemente uno o varios nombres personales. A este tipo pertenecen la bien conocida tésera de París, K.0.2, y además, K.0.2 ${ }^{72}$, K.9.1 = Sup. 94, K.14.1 = Sup. $97^{73}$, a las que desde 1986 hay que añadir K.0.9 ${ }^{74}, K .18 .1^{75}$, K. $29.1^{76}$, y posiblemente K. 0.12 y K. $0.13^{77}$.

Estas téseras, que pueden ser ejemplificadas con la siguiente:

K.0.9: retukeno : uisal / ikum, «(tésera) de Retukenos, (del grupo familiar) de los Visalikos", se pueden dividir en tipos distintos según que se mencione un NP, con o sin indicación de grupo familiar, o tan sólo un grupo familiar. Si algunas téseras dudosas correspondiesen efectivamente a este grupo, también en él, como es en realidad de esperar, podria aparecer un término, generalmente abreviado, relativo a la tésera o al pacto.

En resumen, hasta aqui hemos encontrado téseras en las que se menciona tan solo una de las partes que interviene en el pacto de hospitalidad, en ciertos casos una comunidad politica mencionada indirectamente a través de un adjetivo, en otros un individuo o una agrupación familiar.

Cuando pasamos a las téseras largas nos encontramos en un terreno mucho menos seguro. Algo nos pueden ayudar las téseras latinas, pero creo que nuestra mejor guia son los resultados obtenidos en el análisis de las téseras breves. Los textos son los siguientes $^{7 x}$ : K.6.1 = Sup. 84 (tésera de Luzaga) y K.23.2 ${ }^{79}$, a los que se añaden desde 1986 K.0.10 ${ }^{\times 0}$ y K. $0.11^{\times 1}$. Rasgo común a todos estos textos es que en ellos se menciona a las dos partes pactantes, pero pueden contener otros datos que complican su interpretación hasta el punto de hacerlos incomprensibles por el momento. Un ejemplo relativamente simple nos lo proporciona la llamada tésera de Arecorata:

\section{K.0.11: A arekoratika : kar}

B sekilako : amikum : melmunoś / ata

C bistiro : laśtiko / ueisoś.

La línea A coincide plenamente con el posible texto de una tésera unilateral en que se menciona a una comunidad política, la $\mathrm{B}$ con el de una tésera unilateral en que se menciona a un individuo ${ }^{{ }^{2}}$, es decir tenemos combinados los dos primeros grupos que hemos visto. El caracter de la línea $\mathrm{C}$ es mucho más hipotético, pero biśtiroś tiene paralelos como NP y ueisoś es un nominativo concertado con ese $\mathrm{NP}$, cuyo dativo, ueisui, aparece en la tésera de Luzaga, y debe significar un cargo que juega algún papel en el área institucional a la que pertenecen los pactos de hospitalidad. Aunque carece de paralelos laśtiko tiene que ser el genitivo de un NP *laśtikoś que designará al padre de Pistiros. La línea $\mathrm{C}$ por lo tanto contendrá posiblemente un tercer dato relati-

${ }^{7 x}$ No incluyo en la clasificación K.18.2 Labeaga, J. C. \& Untermann, J.: 1993/94: "Las téseras», p. 50 - porque se encuentra en un estado que no permite pronunciarse. Tampoco incluyo algunas téseras inéditas que conozco pero que van a ser publicadas por sus descubridores.

7 Garcia Merino \& Albertos: 1981: «Nueva»: 1985: "Una nueva"; Untermann: 1990: "Comentarios", pp. 366-367, con texto que en mi opinión debe ser corregido.

"*i El texto en Untermann: 1990: "Comentarios", pp. 360-361. dependiente de la fotografia en Burillo, F. et alii: 1988: Celtiberos, p. 184, está incompleto. La tésera menciona las dos partes pactantes, contiene la palabra kortika, y tal vez incluya también la mención de un testigo o magistrado. Agradezco a F. Burillo el conocimiento de este texto completo.

k) Untermann: 1990: "Comentarios", pp. 365-366; Gorrochategui: 1990: "Consideraciones», pp. 296-302; Burillo: 1993: «Una tésera".

*2 La expresión "unilateral» procede de Untermann - 1990: "Comentarios", p. 359- y es una forma adecuada de referirse a las téseras en que sólo se menciona a una de las partes. 
vo al establecimiento del pacto, mencionando por ejemplo un magistrado que ha actuado como testigo o como responsable de su formalización.

En resumen, las téseras de hospitalidad parecen ser pactos entre dos partes de distinta magnitud, por un lado un individuo o un grupo familiar, por otro una comunidad politica. Las téseras breves incluyen simplemente la mención de una de las partes. En el primer grupo se menciona por medio de un adjetivo a la comunidad politica pactante; probablemente estas téseras estaban en poder de los individuos o grupos familiares que habian pactado con esa comunidad, a la que naturalmente no pertenecian; el pacto les confería quizá unas ciertas garantías juridicas similares a las que poseian los miembros por nacimiento de la comunidad en cuestión ${ }^{\times 3}$. En el segundo grupo tenemos textos que mencionan a un particular o a un grupo familiar. Representan el tipo complementario del que previamente hemos mencionado, aunque también podrian testimoniar pactos entre grupos familiares e individuos, o entre dos individuos. Al tercer grupo, en el que se mencionan ambas partes pactantes, pertenecen las téseras que plantean auténticos problemas de interpretación.

En el caso de las téseras, como en el de la epigrafia rupestre, el uso de la lengua celtibérica no desaparece con el de la escritura ibérica. Junto a las téseras ya comentadas y a las propiamente latinas, en escritura y lengua latina por muchos rasgos indigenas que conserven, existe un pequeño grupo de téseras en escritura latina y lengua celtibérica cuyas características las aproximan más a las primeras que a las segundas ${ }^{84}$. El tipo más simple no sólo de los que conocemos sino de los posibles, el mero nombre propio, plantearia problemas de identificación, ya que como propio puede no pertenecer propiamente ni al sistema del latín ni al del celtibérico, y para adscribir la tésera a una u otra lengua necesitariamos algún rasgo gramatical definido que puede faltar. La tésera atulikum (K.0.6) por ejemplo aparecería en alfabeto latino probablemente como ATVLIQVM, tanto si el grabador pretendía expresarse en esa lengua como si pretendía hacerlo en celtibérico.

* En principio acepto la opinión común que, de acuerdo con los documentos latinos, ve en las téseras celtibéricas testimonios de pactos de hospitalidad. Conviene señalar sin embargo que, en una sociedad como la celtibérica, la hospitalidad podria no ser la única relación en que una contraseña con nombres resultase conveniente. Asi lo indican al menos los paralelos griegos primitivos - $c f$. Gauthier, op. cit. - , pero de momento carecemos de cualquier indicio concreto en Hispania.

"4 Vid. ahora Untermann: 1995: «Epigrafia», pp. 202-204.
El tipo siguiente en simplicidad es el de libiaka / koirtika : kar (K.0.4), representado en alfabeto latino por el hallazgo reciente de Monte Cildá (PA, $\mathrm{K} .31 .1)^{\mathrm{K}}$. Se trata de una tésera del tipo de manos entrelazadas en bulto semirredondo en la que se lee TVRIASICA / CAR, que ha sido puesta en relación con Turiaso como testimonio de un pacto entre esta ciudad y la del lugar del hallazgo, posiblemente la Vellica de las fuentes, pero en ese caso esperariamos *TVRIASONICA. Tenemos que pensar más probablemente en una base *Turiasia/ ${ }^{*}$ Turiasa/*Turiasium/*Turiasum en el supuesto habitual de que la formación en $-V$ - $k a$ esté formada sobre un NL, aunque en realidad no cabe excluir la posibilidad de un derivado de un NP, es decir de *Turiasus.

Las restantes tésaras en escritua latina, K.7.3, K. 14.2 y K.15.1 ${ }^{\text {*o }}$, plantean aún, a pesar del reciente estudio de J. Untermann, problemas de interpretación, e incluso an algún caso no asequible en la actualidad, de lectura, pero lo más probable es que todas ellas, o al menos las dos primeras, contengan mención, a veces con abreviaturas poco claras, de las dos partes pactantes. En el caso de K.15.I cabria la posibilidad de que sólo incluyese la referencia a un individuo, CAISAROS, con indicaciones adicionales como el patronimico.

10. Además de las téseras existen algunos pequeños bronces celtibéricos cuya clasificación plantea problemas. En general se tiende a interpretar como tésera cualquier objeto metálico menor con texto celtibérico que no tenga otra función obvia, pero en realidad no hay motivo para excluir otras posibilidades cuando el análisis del texto por sí mismo no demuestra que efectivamente se trata de una tésera. Los pequeños bronces en cuestión son K.0.7, K.0.14, K.0.15, K.1.2 y K.21.1. K.0.7 es sin duda el más interesante, si exceptuamos K.0.14 sobre cuya autenticidad tengo dudas que, hasta que no exista un análisis técnico de la pieza, me aconsejan prescindir de ella ${ }^{87}$. K.21.1 es un fragmento demasiado pe-

\footnotetext{
*s Peralta, E.: 1993: "La tésera».

*6 Bibliografia anterior en Untermann: 1995: "Epigrafia», pp. 202-203. Vid. también Curchin, L. A.: 1994: "The Celtiberian" (K.14.2 y K.15.1). Ambos AA, vuelven a la lectura de Fita en la tésera de Paredes de Nava, probablemente con razón.

* Hay varios indicios, aunque ninguno se puede considerar una prueba; el más significativo es la forma retukeno con una ke tumbada que no se justifica en el texto ni tiene paralelos. La palabra entera parece copiada de K.0.9, en donde la adaptación a la forma de delfin de la tésera justifica la postura anómala del signo. Entre tanto K.0.14, el llamado "bronce res", ha dado lugar a varios estudios: Burillo: $1989-1990$ (1993): "Un nuevo"; Meid: 1994: Celtiberian, pp. 45-55.
} 
queño para poder identificar su función ${ }^{\mathrm{x}} ; \mathrm{K} .1 .2$ es una placa de bronce decorada procedente al parecer de excavaciones clandestinas en Botorrita que se reutilizó como soporte de escritura, pero que ha llegado a nosotros en un estado tan fragmentario que es imposible pronunciarse sobre su función ${ }^{89} ;$ K.0.15 es un pequeño cuadrado de bronce de grosor superior al esperable en una tésera o tablilla inscrita ${ }^{\% 0}$, pero no sé si adecuado para una pesa ya que no conozco su peso, que carece una vez más de procedencia conocida y por lo tanto no está libre de sospechas $^{91}$, y en todo caso no es clasificable por el momento. Sólo cabe por lo tanto comentar el llamado «bronce de Cortono»:

K.0.7: Jrboś oboi_: kortono: / alabom_:iko. ueitui / aŕkatobesom / loutu / loukaiteitubóm / tureś /buńtaloś : koŕtonei.

Una vez más su procedencia es ignorada, pero parece auténtico por algunas peculiaridades gramaticales que dificilmente habiesen sido asequibles a un falsario en la fecha de su aparición. Se le ha interpretado como tésera de hospitalidad ${ }^{92}$, y es posible que asi sea pero faltan elementos probatorios. La organización del texto, ciudadosamente pautado, aisla al final una especie de firma, «Buntalos en Cortono", que podría corresponder también a la mención como tercer elemento del testigo o magistrado actuante en un pacto de hospitalidad que hemos visto en algunas téseras. El comienzo de la primera línea no es legible, pero sí queda clara la secuencia final... -oboi kortono, que podría corresponder a un dativo de tema en -o- con /o:/ conservada, determinado sin duda por un genitivo, "de Kortono». El dativo podría indicar una de las partes beneficiarias de un pacto de hospitalidad, pero en ese caso en las téseras conocidas la otra parte parece ir indicada en nominativo. Una especie de dirección parece una hipótesis a considerar, y de hecho, si no se tratase de un bronce, la estructura general del texto parecería compatible con una misiva de algún tipo. En cuanto

${ }^{k 8}$ Galindo, P. \& Domínguez, A.: 1985: «El yacimiento», p. 591.

kง Beltrán Martinez: 1983: «Epigrafia», pp. 101-103.

90 Fletcher, D. \& Pérez Vilatela, L.: 1994: «Dos textos», pp. 357-361.

91 Sobre todo teniendo en cuenta que aparte un NP bien conocido, letontu, el resto de la inscripción es anómalo: aus : śot, con $\langle$ s $>$ del tipo Luzaga, Caminreal, Monsanto y K.0.7, muy distinto del de Botorrita, $y$ un último signo dificilmente identificable aunque tiene un parecido no muy próximo al signo $\langle s\rangle$ de Botorrita invertido, por lo que los editores han leido sos, es decir una forma pronominal atestiguada en Botorrita 1 , lo que gramaticalmente tampoco resulta muy satisfactorio.

${ }^{2}$ Fatás: 1985: «Una tésera»; Untermann: 1990: "Comentarios», pp. 367-369. al vocabulario, falta el específico de las téseras, aunque ueitui podria ser una variante gráfica o fonética de ueisui, atestiguado en la tésera de Luzaga y en nominativo en la de Arecorata (K.0.11). La única otra palabra para la que se ha hecho una propuesta de interpretación es arkatobesom ${ }^{43}$, y de ser correcta esa propuesta difícilmente se conciliaría con una tésera de hospitalidad. En resumen, el bronce de Cortono puede ser un indicio de que todavia desconocemos clases enteras de documentos celtibéricos de cierto interés institucional, ya que sin ese interés no se justificaria el uso del bronce.

11. El primer bronce celtibérico de Botorrita apareció en 1970 en las llamadas «Eras Bajas», término de Botorrita, a unos veinte kilómetros al sur de Zaragoza, sobre el río Huerva y al pie del Cabezo de las Minas, donde se asentaba la antigua acrópolis de Contrebia Belaisca, ciudad de la que procede, además de Botorrita 1 y algunas piezas menores ya mencionadas y del bronce aún mayor del que enseguida me ocuparé, un bronce latino republicano ${ }^{94}$. La zona arqueológica de «Eras Bajas» corresponde a un conjunto de construcciones al parecer de carácter agricola de las que formaba parte un patio en el que aparecieron los dos fragmentos del Bronce, ambos sin duda fuera de su contexto original aunque no necesariamente muy alejados. Los materiales que permiten fechar el momento de destrucción de la zona son fragmentos de cerámica campaniense $\mathrm{B}$ y $\mathrm{C}$, y una lucerna de tipo romano republicano. Como fecha ante quem tanto de Botorrita 1 como de los restantes grandes bronces - el romano está claramente fechado en el 87 a.C.- se impone la de la destrucción de la ciudad, fijada por las investigaciones de $\mathrm{M}$. Beltrán en época sertoriana ${ }^{95}$.

Un problema que no queda claro desde el punto de vista arqueológico, pero que el análisis interno del Bronce permite dar por resuelto, es el de la relación entre ambos fragmentos y ambas caras escritas; se trata de un documento único, redactado probablemente por una sola mano ${ }^{96}$. La cara A consta de once líneas que se extienden a todo lo largo de ambos fragmentos, la cara B de nueve que, en general, no traspansan los límites del fragmento mayor,

\footnotetext{
${ }^{43}$ Untermann: 1989: "arganto- ".

44 Beltrán Martinez, A. \& Tovar, A.: 1982: Contrebia, pp. $7-22$.

95 Beltrán Lloris, M.: 1986: «Introducción», p. 498; 1987: "La España», pp. 272-274.

96 Tovar, op. cit., 63. Es también mi impresión después de haber examinado por tres veces el original del Bronce. Tovar se fija esencialmente en el comienzo de la linea 8 de la cara B, para mi son aún más probatorias las líneas 6 y 7 .
} 
aunque el primer trazo de la primera letra de la sexta y la séptima se han perdido en la fractura y por lo tanto fueron grabados con anterioridad a ésta ${ }^{47}$. La escritura de ambas caras corresponde a una misma tradición paleográfica; hay una cierta diferencia entre los signos de la cara $\mathrm{A}$, más pequeños y más cuidados, y los de la cara B, pero nada se opone a que en ambos casos la mano de escriba haya sido la misma, trabajando con más descuido en la cara B que, como veremos, tiene un carácter secundario con respecto a la $\mathrm{A}$.

El bronce fue publicado por A. Beltrán, tras algunas noticias previas, en $1974^{\circ \mathrm{x}}$, y su interpretacción tiene tras de sí una ya complicada historia que he resumido en otro lugar ${ }^{94}$. No hay que olvidar que también en 1980 se halló el bronce latino, publicado con ejemplar rapidez por G. Fatás, que naturalmente contribuyó a poner de manifiesto el interés arqueológico de Contrebia Belaisca, pero además facilitó en algunos puntos, especialmente onomásticos, la interpretación del bronce celtibérico ${ }^{100}$. De hecho puede decirse de la cara B que se trata, sin duda, de una lista de personas caracterizadas por un titulo y correspondientes a distintas subdivisiones, locales o de otro tipo, dentro de la comunidad civica de Contrebia Belaisca, lo que a su vez parece indicar que el texto contenido en la cara A tiene carácter público y una cierta importancia, juridica o religiosa, para esa comunidad. Pero la cara $\mathrm{A}$, a pesar de una nueva serie de intentos de interpretación global basados en la nueva lectura ${ }^{101}$, sigue resultando incomprensible, en el sentido de que, incluso cuando alguno de los intentos de traducción no es demostrablemente falso y reúne las características básicas que debe poseer un desciframiento textual, es decir no chocar directamente con el sentido co-

\footnotetext{
${ }^{97} C f$. nota anterior.

9* Beltrán Martinez: 1974: «La inscripción».

"Hoz, de.: en prensa: "The Botorrita». Bibliografia básica hasta la limpieza del bronce: Lejeune: 1973: «La grande»; Hoz, J. de. \& Michelena, L.: 1974: La inscripción; Tovar: 1973: «Las inscripciones»; 1975: "Ein neues Denkmal»; Maluquer: 1974: "El bronce»; Adrados, F. R.: 1976: «Aportaciones»; Mariner. S.: 1976: "Botorrita»; crónica de Actas del I Coloquio; 1976, p. 8; Schmidt, K. H.: 1972 (1976): «Der Beitrag"; 1976 «Zur keltiberischen Inschrift»; 1976: "Historich-vergleichende Analyse»; Fleuriot, L.: 1975: "La grande»; 1979: "Etat»; Gil, J.: 1977: "Notas». Hay que señalar también alguna observación de detalle anterior a 1980; la bibliografia se puede encontrar en de Hoz: 1982: «Crónica 1981», pp.300-302. Tras la limpieza: Porta, E.: 1982: "La restauración»; Beltrán Martínez, A. \& Tovar, A.: 1982: Contrebia: y vid. infra.

100 Fatás: 1980: Contrebia.

101 Hoz, J. de.: 1986: "La epigrafia", pp.77-88 y 101-102; Eska, J. F.: 1989: Towards; Eichner, H.: 1989: «Damals»; Meid, W.: 1993: Die Erste; 1994: Celtiberian, pp. 7-28.
}

mún - cuestión ésta bastante desatendida por algunos descifradores de textos antiguos - , coherencia gramatical interna y con respecto a lo que sabemos del sistema gramatical en que se integra el texto, y verosimilitud histórica en varios sentidos que no es éste el lugar de desarrollar, no por ello el desciframiento queda demostrado, ni tampoco alcanza un alto grado de probabilidad. Hacen falta pruebas especificas, que normalmente sólo aparecen cuando podemos traspasar a otros textos los criterios en que se basa el pretendido desciframiento, es decir cuando éste muestra capacidad de predecir, y dado lo escaso de los materiales celtibéricos no es posible aplicar por ahora esta comprobación. A pesar de todo creo que podemos pretender que entendemos la estructura general del bronce en cuanto documento porque sus diversas partes o contienen repeticiones que se justifican mutuamente a la luz de otros documentos antiguos en lenguas conocidas o contienen elementos celtibéricos ya comprobados, NNP por ejemplo. Creo, como creia en 1974, que esa estructura es la adecuada para un documento normativo, algún tipo de reglamento, pero sólo un mejor conocimiento del bronce permitirá comprobar si la expresión lex sacra que utilicé entonces es adecuada; lex confiere al texto una dignidad que no sé si es la que le corresponde, pero por el momento los textos de otras culturas antiguas que parecen más prometedores como paralelos son las leyes epigráficas; en cuanto a sacra, la justificación del uso de esa palabra estaba sobre todo en la interpretación de tokoitośkue sarnikiokue como NND, algo que ahora no me parece tan seguro aunque no sea improbable $^{102}$. En todo caso creo que estamos ante un documento normativo, de referencia posible aunque no seguramente religiosa, cuya estructura general entendemos ${ }^{103}$, y eso nos permite plantearnos la posible existencia de paralelos en otras culturas antiguas, sobre todo en la Italia republicana, que permitan entender mejor la función del bronce en su contexto histórico. Ese enfoque fue el que adopté en 1974, en el libro escrito en colaboración con Luis Michelena ${ }^{104}$, y en un artículo de 1986, y en el que ahora

102 En contra de que se trate de NND Adrados, F. R.: 1976: «Aportaciones», p. 27; Gil, J.: 1977: «Notas», p. 165; Fleuriot, L.: 1979: «La grande inscription», pp. 422-423; Eska, J. F.: 1989: Towards, pp. 17, 94-95, 113-114; Villar: 1990: "La linea inicial», p. 389; dudas de Tovar en Beltrán Martinez, A. \& Tovar. A.: 1982: Contrebia Belaisca, p. 64. Cf. recientemente Schmidt: 1992: "Problems», p. 52.

${ }^{103} \mathrm{Cf}$. las coincidencias en este sentido entre los distintos autores sistematizadas en de Hoz: en prensa: "The Botorrita".

${ }^{104}$ Hoz, J. de. \& Michelena, L.: 1974: La inscripción. 
insistiré aprovechando el avance en el conocimiento del bronce desde entonces y resumiendo las conclusiones de un articulo que recientemente he dedicado al tema ${ }^{105}$.

Los paralelos latinos presentados en 1974 eran las leyes de Luceria (CIL I' $401=$ ILLRP 504) y Espoleto (CIL I'366 = ILLRP 505 \& 506), y el elemento más significativo en la comparación era el patrón formado por oraciones prohibitivas seguidas de condicionales que crei poder identificar en Botorrita. Esta interpretación general es aceptada en la mayoria de las interpretaciones del bronce ${ }^{10 \%}$, a pesar de las diferentes etimologias propuestas para el fundamental sintagma uta oskues ${ }^{107}$, al igual que generalmente se admite el caracter normativo del bronce.

Otro texto que ya en 1974 me parecía comparable, no sólo en los aspectos en que lo eran las leyes citadas, sino como paralelo para la estructura global de la primera cara del bronce, era la ley volsca de Vellitrae (Vetter $n^{\circ} 222$ ). El problema de esa estructura global es en el que ahora podemos insistir tomando en consideración el conjunto de los textos normativos latinos del siglo II y primera mitad del 1 a. $C^{10 x}$. El bronce se articula en tres componentes principales ${ }^{109}$.

$A)$ enunciado general, con función similar a un título (oraciones I o I-II, líneas I o 1-2)

$B$ ) parte central prescriptiva (II-IX, 2-10)

C) conclusión en que se indica la autoridad responsable, y quizá algunas circunstancias de tiempo (¿fecha?) (X, 10-1), de la que es un suplemento la lista de la cara B.

Una organización tripartita similar, con dos breves componentes que sirven de marco y otro central

105 Hoz, de.: en prensa: "The Botorrita".

106 Vid. Meid, W.: 1993: Botorrita-Inschrifi, pp. 75-78.

107 Referencias en Eska, J.: 1989: Towards, pp. 122-123 y 81-82, y vid, tambièn Meid, W.: 1993: Botorrita-Inschrift, pp. 43,102 y $127-128$.

iox $C f$. lo dicho a propósito de las téseras sobre la dependencia de la epigrafía celtibérica de la latina, y lo que se dirá más abajo en términos generales.

109 Eichner (pp. 52-55) distingue un preámbulo (= 1 y II), dos partes principales $(=I I I-V I I+V I I-I X)$ y una formula conclusiva $(=X)$; Eska (pp. 16-29) no propone una estructura en un nivel superior al de la oración, pero sus títulos para 1 y $X$ son "The heading" $y$ "The proclamation»; finalmente Meid tras afirmar que I "schlägt das Thema an» (p. 34) y II (p. 36) añade "die genauere Spezification des Nichterlauben", interpreta III-IX como "ein mittlerer Block» (p. 41) y piensa que en $X$ «es handelt sich um die offizielle Bestätigung und Verkündigung der im Vorhergehenden niedergelegten Gebote und Verbote durch die an der Beschlußfassung beteiligten und dazu autorisierten Personen" (p. 68). Todos los autores consideran que la lista en B es complementaria de X. Parece por lo tanto que podemos admitir que existe una cierta unanimidad en las líneas básicas de la segmentación del bronce. y más extenso, es por supuesto frecuente en innumerables textos de las más diversas culturas, y la hallamos normalmente en leyes y edictos romanos republicanos, pero resulta significativa la marcada diferencia que existe entre los elementos marco de Botorrita y los correspondientes de los documentos romanos ${ }^{110}$. La indicación de autoridad es no sólo elemento característico de A) sino casi obligatorio en todos los documentos latinos prescriptivos ${ }^{111}$. A veces el dato se combina, como en este caso, con un resumen del texto, en otras ocasiones encontramos información adicional, por ejemplo de fecha. Variantes de este tipo, que no voy a describir aquí, pueden verse en mi artículo ya citado, donde también se discute el bronce latino de Contrebia, único caso aparente en que se menciona una autoridad de la que emana el texto pero no se menciona en su parte introductoria.

En cuanto al elemento B), es obvio que los paralelos no pueden ser muy próximos, puesto que aquí el texto depende más directamente de su argumento, pero sí encontramos en Botorrita I patrones que recuerdan otros normales en los documentos romanos, como ya indiqué en $1974^{112}$, aunque hoy es posible ir más lejos en esa dirección ${ }^{113}$. Resumiendo brevemente parece ser que tenemos equivalentes celtibéricos para los patrones latinos que podemos representar por las fórmulas «neque + imperativo» 114 , «si quis + imperativo», y "qui est $X+$ imperativo». Podríamos sacar la conclusión de que Botorrita 1 sigue básicamente un modelo romano, pero se trata de nuevo de patrones muy comunes, visibles en diversas culturas, y sin negar no sólo el estímulo sino tampoco el modelo romano, me inclino a pensar que las diferencias de organización general entre el documento celtibérico y los romanos implican un cierto grado de tradición local independiente.

La discrepancia más llamativa estriba en la selección de motivos para las partes $A$ ) y $C$ ). Para los romanos al parecer lo primero que era necesario

110 Se ha sugerido (Eska, J: 1989: Towards, pp. 13-16, siguiendo a Fleuriot) que un término de comparación más adecuado para Botorrita 1 serian las leyes municipales de época imperial, ya que proceden de la propia Hispania, pero aparte la distinta cronología y contexto histórico, hay que tener en cuenta que si esas leyes han aparecido en Hispania ha sido por puro azar; se trata de copias locales de documentos que se redactaban en la propia Roma, y su utilidad para nuestro tema, que no se puede negar. deriva de que en ellos se mantenía una tradición latina que estaba ya consolidada en los textos republicanos.

111 Ejemplos en de Hoz: en prensa: "The Botorrita".

112 Hoz, J. de. \& Michelena, L.: 1974: La inscripción, pp. 96-97.

113 Reenvio de nuevo a Hoz, de.: en prensa: "The Botorrita».

114 En todos estos casos, «imperativo» debe entenderse como «imperativo o permisivo». 
conocer acerca de un documento normativo era la autoridad de la que emanaba, su legitimación, mientras que los celtiberos podian dejar ese dato para el final, o incluso prescindir de él, como parece que ocurre en Botorrita 3, quizá porque en su más simple marco constitucional resultaba obvio. Más adelante volveré sobre los problemas de la relación entre documentos celtibéricos y romanos, pero de momento me interesa subrayar que la satisfactoria estructura lógica de Botorrita 1, que primero menciona su tema $(A)$, luego lo desarrolla $(B)$, y finalmente indica la autoridad responsable y probablemente la fecha $(C)$. tiene paralelos independientes de los que el más llamativo me sigue pareciendo el de la inscripción de Vellitrae (Ve. 222) ${ }^{115}$.

12. El tercer gran bronce de Botorrita apareció en octubre de $1992^{116}$, en circunstancias todavia un poco confusas. En todo caso no hay ningún motivo para poner en relación el lugar de hallazgo y la función del bronce, que indudablemente fue desplazado en fecha no determinable, al menos por el momento. Se trata de una placa de bronce plomado, que tuvo en origen c. $52 \mathrm{~cm}$. de altura, c. 73 de anchura y 0,4 de grosor, y que ha llegado a nosotros en un fragmento mayor, correspondiente a los dos tercios izquierdos, de c. $50 \mathrm{~cm}$., otro de dimensiones reducidas, correspondiente al ángulo inferior derecho, y un centenar de pequeños fragmentos correspondientes al tercio superior derecho. Para su exposición la placa estaba provista en su borde superior de dos grupos de tres orificios formando triángulos en algunos de los cuales se conservan todavia los clavos originales.

Afortunadamente la totalidad del texto se encontraba en el fragmento mayor, y aunque sólo una parte es directamente legible porque se encontraba en buen estado en el momento del hallazgo, o porque posteriormente ha podido ser restaurada, la práctica totalidad puede ser restituida gracias a las excelentes radiografias disponibles ${ }^{117}$, a pesar de la fuerte corrosión.

in Wallace, R. E.: 1984: Sabellian Languages, pp. 35-60, con la bibliografia anterior.

16. Diaz Sanz, M.* A. \& Medrano, M. M.: 1993: "Primer avancen, pp. 245-246. En el invierno inmediato la Consejeria de Cultura de la Diputación General de Aragón organizó un equipo de trabajo para el estudio y edición del bronce formado por $\mathrm{A}$. Beltrán Martinez, F. Beltrán Lloris, M.* A*. Diaz Sanz, J. Untermann y J. de Hoz. Los resultados de ese estudio, que se envian a la imprenta por las mismas fechas en que lo hace este articulo - otoño de 1995 - son la base de las páginas que siguen, aunque no todos los autores suscribirian lo que aquí se afirma o se propone.

117 Texto completo: AAVV, El tercer bronce de Botorrita. capitulo IV, en prensa.
El texto comprende dos lineas que corren por la mitad izquierda de la parte superior del bronce, y cuatro columnas, las tres primeras de sesenta líneas, la cuarta de cuarenta ${ }^{11 x}$. De lo dicho anteriormente se deduce que una parte importante de la mitad derecha no se llegó a grabar, tal vez por una mala paginación, tal vez porque ya en la antigüedad se advirtió que el bronce en esa parte tenia serios defectos de fundición.

Distribución de lineas, espacios libres, sangrados, etc., plantean problemas de interés que en algunos casos afectan a la correcta comprensión de la estructura del texto, pero no hay lugar de entrar aqui en esos detalles, que han sido cuidadosamente estudiados por F. Beltrán "i".

Ciñéndonos a lo que el texto en sí mismo nos permite decir sobre su estructura está claro que se trata esencialmente de una lista de personas que ocupa en su totalidad las cuatro columnas. Las dos líneas iniciales, que tienen un tamaño de letra mayor que el de las columnas, deben de ser por lo tanto un titulo o introducción o ambas cosas a la vez, a juzgar por los paralelos en otras epigrafias a los que luego me referiré. Su texto resulta sin embargo por ahora incomprensible, y en cuanto a su estructura gramatical sólo cabe señalar un posible verbo en $3^{\mathrm{a}}$ persona de plural, lo que podría indicar que los miembros de la lista eran sujetos de una acción realizada o, mucho menos probablemente desde el punto de vista gramatical, recibian permiso par realizarla, y un posible demostrativo en genitivo de plural que, como es frecuente en los paralelos mencionados, introduciria los nombres que figuran a continuación.

La lista propiamente dicha contiene 542 palabras que se agrupan en categorias bien definidas, NNP en nominativo (241), en parte desconocidos hasta ahora pero a menudo ya atestiguados en el repertorio celtibérico o de la Hispania indoeuropea, NNP en genitivo (52), normalmente en forma abreviada pero cuya función se deduce de su posición en las entradas de la lista a partir de algunos casos no abreviados, y adjetivos en -ko-, tipo bien conocido en celtibérico en la formación de étnicos, de nombres de grupo familiar y de epítetos de topónimos, en genitivo de plural (201). Además hay varios ejemplos de la conjunción -kue y un corto número de palabras dudosas.

Las entradas de la lista están formadas por dos elementos básicos, los NNP en nominativo y los

\footnotetext{
$11 \times$ Me referiré a las dos lineas superiores como 0.1 y 0.2 , las columnas por su número de orden, seguido, tras punto, del de la linea que deba mencionar, es decir 1.1, 4.5, etc.

110 Capitulo III de AAVV: en prensa: El tercer bronce.
} 
adjetivos en genitivo de plural ( $\mathrm{Gpl}$ ), y se organizan en dos tipos principales pero presentan frecuentes desviaciones del patrón más habitual. El esquema nuclear, tipo A, está formado por esos dos elementos, NP + Gpl, y en él los NNP parecen ser los protagonistas del texto mientras que, dada su aparente función, me referiré a los adjetivos como determinantes. Ejemplos de este simple esquema los tenemos en 1.9, sura matulokum, 1.10, elkua raiokum, etc. Prescindo aqui de alguos ejemplos problemáticos de este tipo.

Un segundo esquema, ligeramente más complejo, tipo $\mathrm{B}$, añade a los dos elementos mencionados un tercero, un nuevo NP, pero que en este caso está en genitivo ${ }^{120}$. La interpretación de estos NNP constituye uno de los problemas más importantes del bronce; de momento los llamaré clasificadores. El número total de NNP atestiguados como clasificadores es dificil de decidir, ya que no todas las abreviaturas son identificables, pero no parece inferior a 27 , mientras que el número de entradas con clasificador es de 45 o 46; en dos ocasiones $(2.38,3.46$ ) dos clasificadores parecen ir juntos. No estamos en condiciones de decidir con seguridad si el clasificador es un elemento necesario de cada entrada, es decir si alli donde no aparece está implicito en el contexto, pero parece más probable que no sea así.

Otros esquemas más complejos, en que aparecen varios NNP, unidos a veces por kue, complican singularmente la estructura del texto, pero sin modificarla en lo esencial. En conjunto las entradas complejas con kue me parecen justificarse porque en ellas figuran elementos entre los que existe una relación especial.

El resto de las entradas complejas, y posiblemente la agrupación de algunos de los elementos que aparecen en el tipo complejo con kue, deben responder probablemente al azar que ha condicionado el proceso de información; cuando los redactores del bronce, o de su minuta previa, recibian un dato lo anotaban, cuando recibian varios juntamente los incluian en una sola entrada si era posible, es decir si pertenecian a un mismo grupo expresado por un determinante, pero dos datos de un mismo grupo podian hacerse accesibles sucesiva pero separadamente, con lo que a la llegada del segundo el primero estaria ya recogido, lo que daría lugar a la presencia de un mismo determinante en entradas distintas pero contiguas tal como está atestiguada en el bronce en varios casos.

\footnotetext{
120 Aunque en algunos casos podrian ser nominativos usados como caso neutro, al margen de las relaciones gramaticales.
}

De acuerdo con lo expuesto, la estructura general del listado en que básicamente consiste el bronce se nos muestra en principio bastante clara, aunque no sin ambigüedades y problemas. Fundamentalmente se trata de una lista de personas representadas en la casi totalidad de los casos por su nombre propio $y$ otros elementos. Es la función real de esos elementos lo que deberiamos comprender para captar el sentido del documento. Ante una entrada como 2.42, koitu kuinikum tirtunoś, uno piensa inmediatamente en fórmulas onomásticas de inscripciones celtibéricas como la tésera de Paris (K.0.2), luboś alisokum atualo ke, o latinas que reflejan hábito celtibéricos, como la tabla contrebiense, LVBBVS VRDINOCVM LETONDONIS F, en que encontramos una secuencia idéntica excepto por la indicación explicita de la filiación al final, que sabemos interpretar como NP + indicación de grupo familiar + NP del padre en genitivo. En principio parecería lógico interpretar 2.42 como «Coitu, del grupo familiar de los Cuinicos, hijo de Tirtu», pero sin embargo existen ciertas dificultades para esta lectura.

El número de NNP correspondientes a clasificadores es muy bajo en proporción tanto al número de personas en cuestión como al de NNP de los protagonistas de la lista a los que determinan. Por otro lado si los clasificadores fuesen padres de los protagonistas esperarariamos, tratándose de dos generaciones sucesivas de una misma comunidad, similares repertorios de NNP, pero en realidad las coincidencias son escasas, sólo afectan a NNP muy frecuentes entre los protagonistas aunque no a todos los que tienen esta condición, y ninguno de los NNP aparentemente no celtibéricos que encontramos en la lista de protagonistas aparece entre los clasificadores. En contrapartida, los clasificadores más frecuentes, que a juzgar por sus abreviaturas y por los casos en que aparece completa la forma de genitivo serian letontu, melmansoś, memu, śkirtu. tirtu y ultatu, no reaparecen en su mayor parte entre los protagonistas.

Por otra parte la comparación del conjunto antroponímico del nuevo bronce con el que ya conocíamos en Contrebia Belaisca también es significativa $^{121}$. Hay que tener en cuenta que hasta ahora lo que conociamos eran NNP de personajes de la aristocracia local, es decir que de existir distintos repertorios onomásticos celtibéricos socialmente delimitados, fenómeno bastante común y casi esperable ${ }^{122}$, la onomástica que hasta ahora conocíamos en Con-

121 Motta, F.: 1980: «Per un'interpretazione»; 1980: "Onomastica»; de Hoz, J.: 1986: «La epigrafia», pp. 91-95.

122 Es un caso bien visible en las Galias. 
trebia seria la de la aristocracia. Pero la proporción en ella entre número de individuos y número de NNP era muy cercana a la que encontramos en el caso de los clasificadores, y muy distinta a la de los protagonistas del nuevo bronce, a lo que se añade que hay una homogeneidad mucho mayor entre los NNP de clasificadores y la previa onomástica contrebiense. aristocrática como hemos indicado, que entre ésta y los NNP de protagonistas, y que hasta ahora en Contrebia faltaban por completo los NNP aparentemente extranjeros, griegos, latinos o ibéricos, que encontramos entre los protagonistas del nuevo bronce pero no entre los clasificadores.

Todos estos datos podrian explicarse, aunque desde luego no constituyen una demostración, en el supuesto de que el listado de NNP de Botorrita 3 se refiera a gentes de condición baja o al menos no elevada, y que, a pesar de la apariencia inicial de entradas como la citada 2.42 , los clasificadores no sean en realidad indicaciones patronímicas.

Ahora bien, el computo de los clasificadores se modifica sustencialmente si hay NNP repetidos, y si excluimos que se trate de patronímicos es posible que tantas veces como se mencione un NP se haga referencia a un mismo individuo. Aún asi las coincidencias y discrepancias de repertorios entre clasificadores y protagonistas de una parte, y entre clasificadores o protagonistas y onomástica previa de otro, son indicio suficiente de la existencia de dos repertorios onomásticos en Contrebia Belaisca, aristocráti el uno. más popular el otro, representados en el bronce respectivamente por los clasificadores y los protagonistas.

Lo dicho sobre los clasificadores afecta directammente a la cuestión de los determinantes. Si el aparente indiscutible patronimico de 2.42 no es probablemente un patronimico, se plantea de inmediato la cuestión de si el aparente indiscutible adjetivo indicador de pertenencia a una familia o agrupación suprafamiliar es realmente tal.

Algunos determinantes coinciden sin más con adjetivos ya atestiguados en fórmulas onomásticas celtibéricas o más frecuentemente de la epigrafia latina del área indoeuropea hispana, pero son sólo dieciseis casos, algunos de ellos poco seguros, de entre 84 determinantes atestiguados en el bronce. Por otra parte los adjetivos parentales se derivan en principio de NNP, y dado el rico repertorio de éstos que nos proporciona el bronce esperariamos encontrar un número alto de coincidencias con el repertorio de determinantes, pero esas coincidencias son mínimas, y lo mismo ocurre cuando comparamos los determinantes con los clasificadores y con la onomástica ajena al bronce.

Otra peculiaridad estriba en la formación misma de los determinantes, entre los que abunda el sufijo -sko- , muy raro entre los adjetivos parentales seguros.

Otro argumento, aunque no muy significativo. contra el caracter de indicación familiar de los adjetivos estriba en la distribución de los repetidos, sin ningún sistema coherente al parecer, $y$ en la frecuencia con la que se suceden entradas distintas con un mismo determinante.

Por último, en algunos casos los determinantes aparecen agrupados en parejas, es decir que el determinante de un NP es a su vez determinado por un segundo adjetivo, fenómeno que no tiene paralelos en los adjetivos de familia tal como conocíamos su uso hasta ahora. Es evidente que en 2.3, loukaniko uiriaśkum, la pertenencia a los Loucanicos y a los Viriascos no son dos adscripciones incompatibles, lo que dada la frecuencia de ambos determinantes, que excluye que uno de ellos represente una categoria anómala, introducida sólo a efectos de diferenciación, hace pensar en la posibilidad de que los determinantes no representen una clase única de grupo, familiar o de otro tipo, sino que incluyan categorias diversas.

Los datos que hemos examinado no permiten sacar ninguna conclusión firme sobre los determinantes; a lo sumo podemos establecer algunas presunciones. Personalmente considero que los determinantes pueden pertenecer a categorias diversas, entre las que sin duda parece haber adjetivos parentales, es decir indicaciones de la organización familiar a la que pertenecian algunos de los protagonistas del bronce, pero pueden existir también indicaciones de otro tipo, profesionales, de status o locales, a las que sólo podremos acercarnos por la vía más que arriesgada del análisis semántico que en este caso sólo puede tener base etimológica, pero con los datos de que disponemos no es fácil o incluso posible llegar a precisar, sobre todo porque en general desconocemos la base sobre la que se ha formado el adjetivo, y porque aunque estuviesemos seguros de haber identificado su etimologia tropezariamos con el problema de que los NNP se forman a menudo sobre bases del vocabulario común, lo que podria impedirnos determinar si el adjetivo en cuestión se habia formado sobre un NP, y era parental, o sobre un lexema común, y era por ejemplo técnico; ante una forma como uiriaśkum no sabemos en efecto si deriva por ej. de un NP *Viriasos o si se ha formado directamente sobre el sustantivo viria ${ }^{123}$.

Hemos llegado asi a la conclusión de que Boto-

123 Viria está atestiguada explicitamente por Plinio ( $\mathrm{NH} 33$, 39. en pl.) como palabra celtibérica; el supuesto NP no aparece sin embargo entre los NNP celtibéricos recogidos por Albertos: 1979: "La Onomástica», y Luján,; en prensa: "La onomástica». 
rrita 3 es una lista de personas a cuyo NP se añaden uno o dos datos que pueden ser la indicación de grupo familiar y el patronimico, o una indicación de grupo no precisable y de relación - ¿dependencia p ej.? con un individuo. Es posible incluso que la preocupación fundamental de los redactores fuese la identificación clara de cada miembro de la lista, más que atenerse a criterios coherentes de denominación. por lo que según los casos utilizasen un tipo de datos u otro, con lo que no seria imposible que ciertas entradas correspondiesen efectivamente a la fórmula de denominación familiar con patronímico o sin él, y otras definiesen al protagonista por su pertenencia a un grupo no familiar, con indicación o no de un personaje con el que ese grupo guardase algún tipo de relación. ¿Pero qué clasificación epigráfica se puede dar a una lista de estas características?

La epigrafia celtibérica es resultado de diversas influencias foráneas, básicamente ibéricas como demuestra la escritura misma utilizada, y latinas como demuestran los tipos de documento, y es en ese contexto de contactos con tradiciones diversas, ya desarrolladas, como debemos intentar valorar los posibles significados de una lista celtibérica.

No faltan ejemplos de listas sobre materiales nobles y no perecederos en el mundo antiguo ${ }^{124}$, resultado de los peculiares condicionamientos intelectuales y las particulares instituciones de la comunidad política que ha decidido su erección, y que en el caso de las ciudades celtibéricas nos son escasamente conocidas. Algunas generalizaciones son sin embargo posibles.La lista es en efecto por su propia naturaleza un documento de caracter práctico, cuyo contexto esperable es un archivo más o menos formalmente definido, en el que se deposita sobre un soporte de fácil manejo y bajo precio. Para que una lista sea inmortalizada en un material noble y para que sea expuesta en público debe recibir una reinterpretación que no puede ser sino ideológica, lo que normalmente implica que los miembros de la lista son importantes políticamente, lo que puede incluir razones económicas, o desde un punto de vista religioso. Hay que recordar sin embargo que un número considerable de los NNP que figuran en el bronce corresponden a mujeres, lo que en la mayor parte de las comunidades poliadas del Mediterráneo antiguo nos llevaría a pensar en una lista relacionada con la religión ${ }^{125}$. Dado lo poco que sabemos de la sociedad celtibérica no tenemos datos para afirmar

124 He reunido posibles paralelos epigráficos a Botorrita 3 en AAVV: en prensa: El tercer bronce, capitulo IX.

125 No faltan listas de mujeres en los paralelos a los que se refiere la $\mathrm{n}$. anterior. o negar la posibilidad de una lista de personas con propiedades o con derechos económicos de cualquier tipo entre los celtíberos, en la que se incluyesen mujeres, pero lo más probable es que finalmente la masiva presencia de NNP femeninos en el bronce se explique porque de una u otra forma éste esté relacionado con el culto o con alguna forma de organización religiosa

13. Una discusión del uso que los celtiberos hacían de la escritura no puede pasar por alto el fenómeno sorprendente de los repetidos hallazgos de grandes bronces epigráficos en Botorrita. Ningún otro yacimiento celtibérico ha proporcionado nada comparable a los tres grandes bronces contrebienses, ningún yacimiento hispánico en realidad, e incluso fuera de la Península Ibérica, en zonas del Mediterráneo donde la civilización ha aparecido antes y se ha desarrollado en época prehelenística o preimperial con mayor sofisticación y con mayor riqueza de variables, una similar sucesión de hallazgos sería algo sorprendente y exigiría una explicación.

Una explicación lógica incluiría dos notas; en primer lugar sería esperable que el yacimiento en cuestión se hubiese distinguido en la antigüedad por características especiales que explicarian la abundancia de documentos sobre un material noble - y en este sentido la abundancia será naturalmente relativa porque en esas circunstancias especiales se podian dar grados muy diversos, una cosa es Atenas y otra Ateste-, y en segundo lugar supondríamos que el lugar había sido objeto de una exploración arqueológica de cierta intensidad. Un ejemplo típico podría ser Olimpia, donde se unen la intensidad del estudio arqueológico y la peculiar posición del yacimiento en el mundo griego antiguo que atrajo no sólo la publicación de textos institucionales de los propios eleos, sino también de inscripciones de muchos otros estados que buscaban una referencia internacional.

Botorrita sin embargo es un yacimiento sólo muy parcialmente excavado, y lo que es más importante, todos los grandes descubrimientos epigráficos se han producido al margen de la excavación regular de la acrópolis, donde según veremos sería de esperar que, de haber existido un digamos nucleo epigráfico público, se hallase éste; por otra parte nada indica que la antigua Contrebia Belaisca jugase un papel especial en el mundo celtibérico que haga esperar en ella una densidad excepcional de hallazgos epigráficos ${ }^{126}$. Lo único excepcional de Botorrita es que, junto con

120 F. Beltrán en AAVV: en prensa: El tercer bronce, capitulo I, propone una posición privilegiada para Botorrita desde el punto 
Numancia, es el único asentamiento celtibérico que ha sido excavado hasta cierto punto, pero como ya he dicho esto no explica los grandes hallazgos; explica tan sólo los pequeños.

Ahora bien, si ni las caracteristicas antiguas de la ciudad ni las modernas de su exploración tienen caracter excepcional, su actual situación anómala debe ser resultado del azar, y por lo tanto lo que podamos deducir de los usos epigráficos de la ciudad podrá ser transferido, con las debidas cautelas, a otras ciudades celtibéricas del mismo ámbito cultural y similar entidad, incluidas por supuesto las probablemente más importantes Segeda o Bilbilis. Ambas cuestiones, azar y caracter no atipico de Botorrita, merecen algún comentario.

Dado lo poco explorados que están los asentamientos celtibéricos podriamos pensar que el azar se reduce a la simple fortuna que ha llevado a clandestinos y a arqueólogos enfrentados en operaciones marginales o de salvamento, no originadas en un proyecto cientifico de exploración, a tropezarse con tres piezas excepcionales, pero como ya he dicho lo que no es normal es que esas piezas se hayan conservado desde la antigüedad en un yacimiento de las características de Botorrita. El azar por lo tanto más que al hallazgo se refiere a la conservación; por azar en la destrucción de Contrebia se salvaron, $\mathrm{y}$ quedaron ocultos, $\mathrm{y}$ por tanto no pudieron ser posteriormente reaprovechados, un cierto número de bronces epigráficos, cuatro al menos, tal vez más. Esto implica que lo que se salvó fue, empleando la palabra en un sentido no técnico, un auténtico archivo. Un archivo propiamente dicho por supuesto no parece que pudiese existir en la Contrebia del siglo 1 a.C., cuando se trataba de una institución recientisima en la propia Roma; lo que sí pudo existir y probablemente existió fue un lugar, sin duda recinto sagrado de algún tipo, en el que la costumbre privilegiase la exposición pública de documentos, contribuyendo con sus propias connotaciones al valor simbólico que, entre otras funciones, poseían sin duda las inscripciones sobre materiales valiosos expuestas a la vista de la comunidad ${ }^{127}$. La multiplicidad de hallazgos en Botorrita podría explicarse por al-

de vista epigráfico por encontrarse en una zona que servia de centro regional a la administración romana, pero aunque esto podria explicar la aparición de otros documentos similares a la tabula contrebiense, dificilmente justifica la multiplicación de epigrafes indigenas digamos autónomos. $\mathrm{E}$ incluso la presencia de la tabula contrebiense en Botorrita parece deberse sobre todo a que se trata de la ciudad «neutral» geográficamente más próxima a las comunidades litigantes.

127 Hay sin duda mucho de cierto en la tendencia reciente a valorar sobre todo en términos simbólicos los documentos pú guna circunstancia relacionada con la ruina de ese recinto, que habria facilitado la preservación de un cierto número de documentos, aunque es preciso reconocer que los datos que se tienen sobre el lugar de hallazgo de los tres grandes bronces no favorecen esa hipótesis.

Pero como ya he dicho no hay ningún motivo para pensar que Contrebia se caracterizase por una más decidida vocación epigráfica que cualquier otra ciudad de la Celtiberia, al menos de la Celtiberia Citerior, e incluso es de suponer que la presencia de epigrafes públicos sería mayor en centros politica y economicamente más significativos como Bilbilis y Segeda. Cabe por lo tanto extrapolar a esas ciudades la existencia de archivos públicos en el sentido informal en que podemos hablar del archivo de Contrebia. Dar un paso más y esperar, puesto que se trata de ciudades totalmente inexploradas ${ }^{12 x}$, que en su dia podamos conocer una parte de esos archivos, es sin embargo pura confusión de la realidad y el deseo, puesto que como ya he dicho el caso de Botorrita debe haber sido de alguna forma excepcional.

14. Entre los celtíberos, aunque sin duda tuvieron que existir textos de tipo económico, no conocemos por ahora ningún caso siquiera meramente posible, $\sin$ duda porque los materiales utilizados eran perecederos. Aún asi resulta significativo que el azar no nos haya conservado ni un sólo testimonio, y más aún el que, al adoptar la escritura ibérica, los celtiberos no hayan a la vez adoptado la costumbre de utilizar el plomo como soporte barato si los usos económicos hubiesen jugado un papel decisivo en el proceso de recepción de la escritura ${ }^{129}$. Esto nos plantea un problema, ya que las motivaciones económicas y un contexto de relaciones mercantiles proporcionan en los casos conocibles fuera de la Peninsula el soporte histórico en el que se produce la transmisión de una ecritura, y lo mismo hemos podido hipotetizar con razones a mi modo de ver de peso en el caso tartesio e ibérico. La cuestión se plantea de forma más confusa en el mundo celtibérico.

En general los indicios que tenemos sobre el

blicos antiguos, aunque quizá se está exagerando en la negación de otras funciones como la comunicativa o la de registro, pero no es éste el lugar para entrar con profundidad en esa cuestión

${ }^{12 \pi}$ Al hablar de Bilbilis no me refiero a la Bilbilis romana, sino a su antecesora celtibérica, cf. Burillo: 1983-1984: "Sobre la situación».

${ }_{124} \mathrm{El}$ plomo en el mundo ibérico parece estar ligado a las actividades económicas tanto en el momento de su introducción. probablemente ligada a la adopción de la escritura, como en sus usos posteriores. Vid. en último lugar de Hoz: 1994: "Griegos». 
desarrollo de la epigrafia celtibérica apuntan a la influencia romana como factor fundamental ${ }^{13}$, tanto en los tipos de documento como en sus soportes. a pesar del hecho indiscutible y de importancia mayor de que la escritura utilizada, con algunas excepciones no muy numerosas y al parecer tardias, fuese una adaptación de la ibérica. No cabe excluir sin embargo que los romanos hayan podido fomentar en Hispania en un primer momento el uso de la lengua ibérica fuera de sus limites originales, como hicieron con ciertas lenguas locales otras potencias conquistadoras en distintos momentos de la historia ${ }^{131}$, y con ello también el uso de la escritura levantina. Sobre la cuestión volveré más adelante.

Los grandes bronces se nos aparecen, desde el punto de vista de la epigrafia latina, como copias libres; la idea de un texto normativo y público fue probablemente romana de la misma forma que el soporte material en bronce es claramente de inspiración romana ${ }^{132}$. El modelo romano debió influir también en la organización interna del texto, al menos en el caso de Botorrita 1 en que esa organización tiene una cierta complejidad, pero por otra parte las posibilidades de organización de un texto normativo en una sociedad de tipo poliado, como Roma todavia lo era aunque en un grado extremo de desarrollo y Contrebia habia llegado a ser aunque en un estadio incipiente, que se expresaba en una lengua indoeuropea, no eran demasiado variadas. Que las coincidencias de patrones entre Botorrita 1 y ciertos documentos romanos fuesen resultado de desarrollos independientes no es imposible. De hecho no hay ninguna relación posible entre el texto volsco ya mencionado y el mundo celtibérico, pero ambos testomonian un modo natural de expresar que una autoridad anuncia un permiso o una prohibición relativa a un lugar, sagrado o no, que tanto en el caso volsco como en el celtibérico podría depender de una tradición de proclamaciones orales.

Una situación similar a la de los grandes bronces es la que encontramos en las téseras de hospitalidad. Las formas materiales, soporte, elaboración artística, estructura de los contenidos, son de origen clásico, pero sirven para dar expresión a instituciones indigenas sin duda de origen prerromano que afectan a la expresión lingüística en ciertos aspec-

\footnotetext{
130 Hoz, J. de.: 1979: "Escritura», pp. 240-243. Vid. ahora Untermann: 1995: "Epigrafia», pp. 197-205; Beltrán, F.: 1995: "La escritura", pp. 174 y 180-183.

131 Sobre las relaciones de los romanos con la epigrafía ibérica Hoz, de.: 1995: "Escrituras».

132 Hoz, J. de. \& Michelena, L.: 1974: La inscripción, pp. 95-96.
}

tos, y la tradición indigena puede modificar incluso el lenguaje figurativo introduciendo la perspectiva cenital propia del mundo celtibérico ${ }^{133}$. Incluso cabria plantearse si los téseras de estructura geométrica compleja, que no parecen tener antecedentes clásicos, y de las que al parecer existen ejemplares anepigrafos, no continuarian una tradición de contraseñas puramente local, anterior a la aparición de la escritura.

Tradiciones diversas, preliterarias, existieron sin duda con anterioridad a la recepción de la escritura por los celtiberos, y al margen de si esa recepción fue previa o no a la llegada de los romanos, la influencia de éstos se ejerció sin duda, en parte al menos, sobre tradidiciones de ese tipo. En Botorrita 1 la materialidad de la tabla de bronce denuncia la presencia romana pero las peculiaridades que en su momento mencioné delatan el caracter indigena del documento, mientras que existirian sin duda rasgos que eran comunes a las tradiciones de romanos, celtíberos y muchos otros pueblos antiguos.

15. Creo por lo tanto que la epigrafia celtibérica se desarrolló probablemente bajo la influencia de prácticas latinas. El problema estriba en determinar si ese estímulo fue exclusivo, es decir si los celtiberos adoptaron la escritura ibérica ya bajo influjo romano, o si se ejerció sobre una epigrafia celtibérica previa, menos desarrollada, y en ese caso en qué fecha recibieron la escritura los celtiberos. En realidad carecemos de datos por el momento para dar una respuesta medianamente razonable a estas cuestiones, pero creo que podemos establecer tres hipótesis posibles conciliables en mayor o menor grado con nuestra información, que el progreso futuro de los descubrimientos permitirá matizar o en su caso excluir.

Los romanos han podido ser el factor determinante que ha llevado a los celtíberos a adoptar la escritura ibérica ${ }^{134}$. En ese caso las relaciones institucionales entre el poder romano y las comunidades celtibéricas habrian sido un cauce imaginable en el que éstas habrian podido advertir ventajas suficientes en el documento escrito, portador de una seguridad menos precaria que la de la palabra de un general u oficial romano, que podría haberlas llevado a requerir los servicios de escribas ibéricos. En los primeros momentos del contacto entre celtíberos y romanos parece obvio que estaba excluida la posi-

\footnotetext{
131 Romero, F.: 1976: Las cerámicas, pp. 157-159.

134 Es significativo que a pesar del uso de la escritura ibérica las inscripciones celtibéricas pertenezcan en general a tipos distintos de los ibéricos, como hemos visto supra y ya se indicaba en de Hoz \& Michelena: 1974: La inscripción, pp. 94-95.
} 
bilidad de que aquéllos pudiesen disponer de escribas que utilizasen el alfabeto latino. Por otra parte en las zonas fronterizas con el mundo ibérico las primeras relaciones entre romanos y celtiberos han podido desarrollarse utilizando como lengua vehicular la lengua ibérica ${ }^{135}$, bien porque fuese la única que poseian en común algunos celtíberos y algunos romanos, bien porque utilizasen los servicios de intérpretes ibéricos que podian ser a la vez escribas. Por último no hay que olvidar la posibilidad. con buenos paralelos históricos, de que los romanos, una vez que se hubiesen familiarizado con la lengua y la escritura ibéricas en los primeros momentos de la conquista - tal vez aprovechando esperiencias previas de comerciantes itálicos-y hubiesen comprobado su amplia difusión como lengua y escritura de civilización y comercio, la hubiesen adoptado de forma sistemática para sus relaciones con los diversos grupos indigenas, fomentando su uso y contribuyendo a su expansión. En el caso de los celtiberos este esquema encajaria particularmente bien con el desarrollo de las acuñaciones, que al ser de inducción sin duda romana podrian haber recibido su alfabeto como una creación artificial en el marco de unas relaciones de dependencia que podian ir desde la simple apropiación territorial a la imposición de un tributo sin presencia efectiva romana. En todo caso los romanos habrian sido conscientes de la extensión y la importancia politica del conglomerado celtibérico $y$, sin renunciar al uso de la escritura ibérica, habrian impulsado la adaptación de ésta a la lengua céltica local, introduciendo así la escritura junto con la moneda en territorios donde antes no se utilizaba, y propiciando a la vez la aparición de otros usos epigráficos más complejos que las leyendas monetales. Dentro de este esquema la aparición de la escritura en la sociedad celtibérica se situaría en una fecha no exactamente precisable pero poco posterior a los primeros contactos intensos de romanos y celtíberos, lo que de momento no está en contradicción con los indicios cronológicos que poseemos sobre los documentos conservados. Por supuesto esta hipótesis quedaría automáticamente desautorizada con la aparición de cualquier inscripción celtibérica fechada en el siglo III a.C., pero de momento contra ella sólo existe una objección de peso, la variante de escritura celtibérica de tipo occidental o meridional, escasamente utilizada en las

13s Entiendo por mundo ibérico el de cultura material ibérica, en el que se utilizaba como lengua vehicular el ibérico, con independencia de la lengua que se hablase localmente, $c f$. $\mathrm{Hoz}$ de.: 1993: «La lengua». En ese sentido, algunas zonas orientales del mundo celtibérico han podido formar parte del mundo ibérico. monedas incluso en su zona propia ${ }^{136}$. Tanto si se trata de una variante arcaica, rápidamente sustituida en el valle del Ebro por el tipo Botorrita que es a la vez el normal en la epigrafía monetal, como si nació en la zona de Luzaga por estimulos llegados directamente del mundo ibérico del S.E. o al menos edetano, no es fácil ponerla en relación con la presencia romana, y por otro lado, si es un resultado exclusivo del encuentro de celtiberos e iberos no se ve por qué no habria ocurrido lo mismo con la otra variante que es la utilizada precisamente por los celtiberos más iberizados en su cultura material ${ }^{137}$.

En una segunda hipótesis podriamos suponer que la ausencia de documentos económicos celtibéricos es puro azar, y que, como en otros casos en la $\mathrm{Pe}$ ninsula Ibérica, la adopción de la escritura por parte de los celtíberos ha respondido al modelo usual en el Mediterráneo antiguo, es decir que se ha producido en el contexto de activos contactos mercantiles con el mundo en que se utilizaba la lengua y la escritura ibéricas. La información arqueológica no parece ser por el momento lo bastante precisa como para apoyar o negar esta hipótesis, pero desde luego no hay indicios positivos a su favor y si una objección importante a la que ya me referi antes. Si los celtíberos hubiesen recibido la escritura ibérica en ese ámbito de relaciones no es verosímil que no hubiesen recibido junto con ella la costumbre de servirse de tablillas de plomo como soportes de escritura, $y$ en ese caso resulta casi increible el que no nos haya llegado ningún testimonio a pesar de las limitaciones de la exploración arqueológica del mundo celtibérico, máxime tras los ya bastantes años que los buscadores clandestinos llevan saqueando impúnemente el territorio con ayuda de detectores de metales.

Nos queda finalmente una última hipótesis que no tiene ninguna objección importante en su contra, aunque por su propia naturaleza dificilmente pueden esperarse testimonios positivos que la apoyen. La influencia cultural ibérica en ciertas comunidades celtibéricas ha sido sin duda muy fuerte; los grupos dominantes celtibéricos han debido participar más directamente de esa influencia, que probablemente se ejerció en parte a través de las relaciones de hospitalidad entre las aristocracias locales

\footnotetext{
13n Hoz, J. de.: 1986: "La epigrafian, pp. 52-55.

137 F. Beltrán - 1995: "La escritura", p. 174- y J. Untermann - 1995: "Epigrafia», p. 197 - aunque inclinándose también a ver el estimulo romano en la expansión de la epigrafía celtibérica, cuentan con una cierta alfabetización anterior inducida por los iberos.
} 
de una y otra cultura. Podemos imaginar en ese contexto, en el que sin duda hay que contar con celtíberos que hablaban además de su lengua alguna de las lenguas vecinas, euskera en ciertas zonas del valle del Ebro, la lengua de los sedetanos fuese cual fuese en otras ${ }^{13 x}$, que el ibérico como lengua vehicular alcanzó también a los celtiberos y con ella la escritura por medio de la cual se expresaba. Que algún aristócrata celtíbero, habituado ya a convivir con el mundo escrito ibérico, se decidiese a adaptar a su lengua el semialfabeto levantino, resulta un episodio verosimil; una vez realizada la adaptación, en realidad las adaptaciones puesto que sabemos que al menos fueron dos, seria preciso, a falta de las ventajas prácticas concretas que juegan el papel fundamental en las adaptaciones en un contexto comercial, que un número importante de los pares del adaptador viesen con él el interés de la escritura como recurso simbólico para expresar permanentemente valores o referencias institucionales, caso de las téseras de hospitalidad, y asegurasen asi el apoyo colectivo imprescindible para que una escritura se consolide y se transmita a las generaciones sucesivas a través de un sistema organizado de enseñanza. Los tipos de documento conservados no contradicen en absoluto esta hipótesis, que en principio implicaría una fuerte limitación social en el uso de la escritura entre los celtiberos, aunque en un segundo momento se podria haber producido una cierta transmisión vertical en el interior de su sociedad. Hallazgos futuros permitirán quizá definir mejor el nivel social en que se desenvolvía la escritura celtibérica, pero por ahora los pocos grafitos cerámicos, únicos testimonios que no tienen claramente un caracter público o aristocrático, no permiten sacar conclusiones, aunque es curioso que en el único caso en que proceden de una excavación moderna y bien controlada, hayan sido hallados en lo que es sin duda un edificio de excepcional factura arquitectónica ${ }^{139}$.

Esta última hipótesis no es sólo la única que no suscita alguna objección importante sino que implica un modelo que permitiría explicar otros casos de adopción de la escritura en los que el modelo económico no parece válido. Podría ser aplicado por ejemplo en la propia Peninsula Ibérica al caso de la escritura del S.O., en el supuesto de que el desarro-

${ }^{13 \times}$ El juicio contrebiense nos indica que un sedetano podia llevar un NP vascónico - Fatás: 1980: Contrebia, pp. 95-96pero eso no nos dice nada sobre la lengua local, tan sólo sobre las relaciones culturales de la zona. Sobre la compleja situación lingüistica de la zona vid. de Hoz: en prensa: «El poblamiento».

139 Vicente et alii: 1993: «Las inscripciones», pp. 749-750.
Ilo futuro de la investigación no permita justificar dentro del modelo mercantil el uso de una versión simplificada de la escritura tartesia por los habitantes de las pequeñas comunidades a las que corresponden las necrópolis de la cultura del Hierro I del S.O., y excluya el que, además de las lápidas sepulcrales, de obvio valor simbólico y correspondientes a un número muy restringido de sepulcros dentro de cada necrópolis, hayan conocido con carácter no excepcional otros tipos de epigrafe. Igualmente ciertos casos de adopción de la escritura en Italia y Asia Menor, así como la expansión del alfabeto a algunas zonas periféricas del mundo griego, y desde luego la aparición de la escritura libica, podrian explicarse con un modelo similar.

16. En conclusión creo que la epigrafia celtibérica representa un caso más del modelo epigráfico prehelenístico, aunque uno caracterizado por un uso no excesivamente alto de la escritura. Con ella tenemos cuatro comportamientos epigráficos muy diferenciados en las sociedades paleohispánicas que conocieron la escritura. Los tartesios, las gentes del S.O. y las de la Alta Andalucia no parecen haber conocido ni siquiera el modesto grado de vulgarización de la escritura que se dió entre los celtíberos, y posiblemente podremos decir lo mismo de los turdetanos, herederos de la cultura tartesia, a pesar de las referencias griegas a su cultura literaria. El caso ibérico sin embargo fue diferente, y podemos estar seguros de que la alfabetización entre los íberos fue mucho más lejos que entre los celtiberos, aunque participaban del mismo modelo prehelenístico de uso de la escritura.

En las distintas provincias epigráficas paleohispánicas hay una relación clara entre la estructura social y el uso de la escritura, pero sabemos demasiado poco como para poder precisar de qué modo funcionaba esa relación en los detalles. Como en las restantes áreas de escritura mediterráneas, incluidas hasta cierto punto las mejor conocidas, es decir Grecia y Roma, rara vez podemos pasar de generalidades.

Podemos decir que el uso de la escritura precisa de un cierto grado de desarrollo social y económico, y que por ello no es casual la fecha y las circunstancias en que cada región de la Península se va incorporando a la práctica de la escritura, es decir la cultura tartesia y su zona periférica no más tarde del siglo VII, la cultura ibérica desde al menos el siglo v, los celtíberos tal vez ya en el siglo III en la zona del Ebro, económicamente más compleja, pero sólo con los comienzos de la romanización en la Meseta, el resto de los pueblos paleohispánicos ya bajo domi- 
nio romano y en general sirviéndose de la lengua latina como lengua vehicular y de cultura. Pero desde luego no se trata sólo de una cuestión de progreso cultural, sino más aún de desarrollo económico y social que implica en cada caso de adopción de la escritura la existencia de una sociedad jerarquizada con cierto grado de especialización económica y un comercio relativamente desarrollado.

Podemos decir también que la escritura es necesaria para alcanzar ciertas formas complejas de organización social, pero ninguna de las sociedades paleohispánicas, todas ellas comparativamente simples, puede servirnos como ilustración de ese principio, obvio pero no por ello menos dificil de analizar.

Más allá de las condiciones muy generales que he mencionado no estamos en condiciones de establecer un conjunto de relaciones especificas entre el uso de la escritura y la estructura de una sociedad dada. Nada que podamos detectar en la actualidad podria llevarnos a predecir que la cultura tartesia no desarrollaría una epigrafia más variada y abundante, o que los iberos sentirian su peculiar atracción por el plomo como soporte de escritura documental. El modelo general que he descrito más arriba fue común a jefaturas y a poleis a pesar de la significativa diferencia política entre ambos tipos de sociedades, y aunque es evidente que la ideología cívica desarrollada en muchas poleis pudo contribuir y contribuyó de hecho a la expansión de las funciones de la escritura en ellas, y que la epigrafia y otras prácticas escritas de la Atenas clásica hubiesen sido imposibles sin esa ideología, la mayor parte de las poleis de la misma época no avanzaron gran cosa por ese camino.

En conclusión podríamos decir que la escritura fue adoptada por las diversas sociedades paleohispánicas cuando su desarrollo económico y social habia alcanzado un nivel en que ello era posible, y que en general el volumen, variedad y peculiaridades del uso de la escritura de cada sociedad paleohispánica deben ser considerados a la vez una consecuencia y un elemento integrante de la intrincada combinación de rasgos que definían su cultura.

\section{BIBLIOGRAFÍA}

ABASCAL, J. M. 1994: Los nombres personales en las inscripciones latinas de Hispania, Murcia.

ABÁsolo, J. A. y Marco, F. 1995: "Tipología e iconografia en las estelas de la mitaad septentrional de la Península Ibérica», Roma y el nacimiento, 327-59.
Actas del I Coloquio sobre lenguas y culturas prerromanas de la Peninsula Ibérica (Salamanca. 1974): 1976: Salamanca.

Actas del II Coloquio sobre lenguas y culturas prerromanas de la Peninsula Ibérica (Tübingen. 1976): 1979: Salamanca.

Actas del III Coloquio sobre lenguas y culturas paleohispanicas (Lisboa, 1980): 1985: Salamanca.

Actas del IV Coloquio sobre lenguas y culturas paleohispánicas (Vitoria, 1985): 1987: Vitoria/Gasteiz = Studia Paleohispanica, Veleia 2-3.

Actas del $V$ Coloquio sobre lenguas y culturas prerromanas de la Peninsula Ibérica (Colonia 1989) = Lengua y cultura en la Hispania prerromana: 1993: Salamanca.

Actas del $1^{\text {er }}$ congreso peninsular de Historia Antigua: 1988: Santiago de Compostela.

ADRADOS, F. R. 1976: «Aportaciones a la interpretación del bronce de Botorrita", Actas del l Coloquio, 25-47.

At.Bi:RTos, M $^{a}$. L. 1966: La onomástica personal primitiva de Hispania. Tarraconense y Bética, Salamanca.

- 1979: «La Onomástica de la Celtiberia», Actas /I Coloquio, 131-67.

- 1981: «Organizaciones suprafamiliares en la Hispania antigua (II)", BSAA 47, 208-214. Valladolid.

- 1983: «Onomastique personelle indigène de la Péninsule Ibérique sous la domination romaine», $A N R W$ II 29.2, Berlin, 853-92.

- 1986: Inscripción con caracteres ibéricos en la Cueva de San Garcia (Burgos), Numantia 2, 207 9 (cf. Moure \& Garcia Soto, "Grabados»).

Albertos, M. ${ }^{\text {a L }}$. y Romero, F. 1981: «Una estela y otros hallazgos celtibéricos en Trébago (Soria)", BSAA 47, 199-208. Valladolid.

Almagro-Gorbea, M. ed.: 1993: Los Celtas: Hispania y Europa, Madrid.

ArLegul, M. 1992: «Las cerámicas de Numancia con letrero ibérico", Actas del $2^{\circ}$ symposium de arqueología soriana, Soria, 473-94.

BELTRÁn LLORIS, F. 1986: «Sobre la función de la moneda ibérica e Hispano-romana», Estudios A. Beltrán, 895-906.

- 1993: «La epigrafia como indice de aculturación en el valle medio del Ebro (siglo It a. e. -11 d. e.)", Actas del V Coloquio, 235-72.

- 1995: «La escritura en la frontera. Inscripciones y cultura epigráfica en el valle medio del Ebro", Roma y el nacimiento, 169-95.

BeLtRÁn Lloris, M. 1977: «Novedades de arqueologia zaragozana», Caesaraugusta 41-42, 151-202.

- 1986: «Introducción a las bases arqueológicas 
del valle medio del rio Ebro en relación con la etapa prerromana», Estudios A. Beltrán, 495-527.

- 1987: «La España celtibérica: la II Edad del Hierro en el valle del Ebro", Historia general I 2, 255-295.

Beltrán Martinez, A. 1973: "Avance al estudio del bronce ibérico de Botorrita (Zaragoza)", XII CAN, 451-454. Zaragoza.

- 1974: "La inscripción ibérica sobre bronce, de Botorrita (Zaragoza)», Homenaje a D. Pio Beltrán, 73-85.

- 1983: «Epigrafia ibérica de Contrebia Belaisca (Botorrita, Zaragoza): Inscripciones menores», Homenaje al Profesor Martin Almagro Basch III, Madrid, 99-107.

Beltrán Martinez, A. y Fletcher, D. 1991: «Dos inscripciones ibéricas de Contrebia Belaisca (Cabezo de las Minas, Botorrita, Zaragoza)», Festschrift für Wilheim Schüle zum 60. Geburtstag (Internationale Archäologie 1), Buch am Erlbach, 29-39.

Beltran Martinez, A. y Tovar, A. 1982: Contrebia Belaisca (Botorrita, Zaragoza) I: El bronce con alfabeto "ibérico» de Botorrita. Monografias Arqueológicas 22. Zaragoza.

BERROCAL, L. 1989: «El asentamiento «céltico» del Castrejón de Capote (Higuera la Real, Badajoz), CUPAUAM 16, 245-95.

- 1992: Los pueblos célticos del Suroeste de la Peninsula Ibérica, Madrid.

Bowman, A. K. y Wool., G. eds.: 1994 Literacy and power in the ancient world, Cambridge.

Burillo, F. 1978: "Una nueva tessera de hospitalidad hallada en Fuentes Claras (Teruel)», Boletin Informativo de la Diputación de Teruel 52, 12-16.

- 1980: El valle medio del Ebro en época ibérica, Zaragoza.

- 1983-84: «Sobre la situación de las ciudades celtibéricas de Bilbilis y Segeda», Kalathos 3-4, 287-309.

- 1986: "Sobre el territorio de los lusones, belos y titos en el siglo II a.C.», Estudios A. Beltrán, 529549.

- 1993: «Una tésera de Arekorata. Un nuevo concepto volumétrico en las téseras de hospitalidad celtibéricas", Homenatge a Miquel Tarradell, Barcelona, 559-67.

- 1989-90 (1993): «Un nuevo texto celtibérico: el bronce «res»»), Kalathos 9-10, 313-331.

Burillo, F. et alii 1988: Celtiberos, Zaragoza.

CABrÉ, J. 1910, "La montaña escrita de Peñalba», BRAH 56, 241-280.

Cardito, L. M. ${ }^{a}$; Gal.az, M. y Moneva, M. a D. 1993: «Inscripciones rupestres y su asociación al Arte»,
Boletin AEAA 33, 62-75.

CARO Baroja, J. 1942-43: «Observaciones sobre la hipótesis del vascoiberismo considerada desde el punto de vista histórico", Emerita 10, 236-86, y 11, 1-59.

CASADO, M. ${ }^{a}$ P. 1975: "Yacimientos desde la Edad del Bronce a época romana, en el curso medio del rio Riguel (Zaragoza)", Miscelánea Arqueológica que al Profesor Antonio Beltrán dedican sus discipulos..., Zaragoza, 131-49.

Curchin, L. A. 1994: "The Celtiberian Vocable 'kar' in Two Inscriptions from Central Spain», $Z P E$ 103, 229-230.

- 1994: "Juridical epigraphy and provincial administration in Central Spain», González Fernández, J. ed.: Roma, 87-102.

Degrassı, A. 1965², 1963: Inscriptiones Latinae Liberae Rei Publicae, Firenze.

Diaz Sanz, M. a A. y Medrano, M. M. 1993: "Primer avance sobre el gran bronce celtibérico de Contrebia Belaisca (Botorrita, Zaragoza)", AEArq $66,243-8$.

Dopico, M. ${ }^{a}$ D. 1989: «El hospitium celtibérico. Un mito que se desvanece», Latomus 48, 19-35.

EICHNER, H. 1989: «Damals und heute: Probleme der Erschließung des Altkeltischen zu Zeußens Zeit und in der Gegenwart», Erlanger Gedenkfeier für Johann Kaspar Zeuß, hrsg. v. B. Forssman, Erlangen, 9-56.

ELH 1960: = Enciclopedia lingüistica hispánica I, dirigida por M. Alvar et alii, Madrid.

ESKA, J. F. 1989: Towards an interpretation of the Hispano-Celtic inscription of Botorrita, Innsbruck.

- 1990: «Syntactic notes on the great inscription of Peñalba de Villastar», BBCS 37, 104-7.

Estudios en homenaje al Dr. Antonio Beltrán Martinez: 1986: Zaragoza.

Etienne, R.; Le Roux, P. y Trannoy, A.: 1987: «La tessera hospitalis, instrument de sociabilité et de romanisation dans la Péninsule Ibérique», Sociabilité, pouvoirs et societé. Actes du colloque de Rouen 1983, Rouen.

FAtÁs, G. 1967: «La colección de pesas de telar del Museo Arqueológico de Zaragoza", Caesaraugusta 29/30, 203-208.

- 1980: Contrebia Belaisca (Botorrita, Zaragoza) II. Tabula Contrebiensis. Monografias Arqueológicas 23. Zaragoza.

- 1985: «Una tésera cortonense», Symbolae L. Mitxelena, 425-432.

Fletcher, D. y Pérez Vilatela, L. 1994: «Dos textos celtibéricos de procedencia desconocida», $A P L$ $21,357-366$.

FLEURIOT, L. 1975: «La grande inscription celtibère 
de Botorrita», EC 14, 407-442. Paris.

- 1979: «La grande inscription celtibère de Botorrita. Etat actuel du déchiffrement", Actas del II Coloquio, 169-184.

Galindo, P. y Dominguez, A. 1985: «El yacimiento celtíbero-romano de Valdeherrera (Calatayud-Zaragoza)», XVII CAN (Logroño 1983), Zaragoza.

Garcia y Bellido, A. 1966: «Las Trullae Argénteas de Tiermes», $A E A$ 39, 113-23.

- 1966: "Tessera hospitalis del año 14 de la era hallada en Herrera de Pisuerga», BRAH 159, 149 166.

Garcia y Bellido, A. y Garcia-Blllido, Ma. P. 1993: Album de dibujos de la colección de bronces antiguos de Antonio Vives Escudero, Madrid.

Garcia-Bfllido, M. ${ }^{\text {a }}$ P. 1993: «Origen y función del denario ibérico", Sprachen und Schriften, 97-123.

- 1995: "Célticos y púnicos en la Beturia según los documentos monetales", Celtas y túrdulos: la Beturia, Cuadernos emeritenses 9, Mérida, 255292.

- en prensa: «Los ámbitos y función de la moneda en la Hispania republicana».

Garcia Garrido, M. y Pellicer, J. 1984: «Dos téseras de hospitalidad celtibéricas en plata», Kalathos 3-4, 149-54.

Garcia Merino, C. 1980: "Una tessera hospitales de Uxama (Soria)», BSAA 46, 206-219.

Garcia Merino, C. y Albertos Firmat, M. ${ }^{\text {a }}$ L. 1981 : «Nueva inscripción en lengua celtibérica: una tessera hospitalis zoomorfa hallada en Uxama (Soria)"), Emerita 49, 179-189. ( con un suplemento en Emerita 50, 1982, 365 ss.).

Garcia Merino, C. y Albertos Firmat, Ma L. 1985: "Una nueva Tessera hospitalis con texto en lengua celtibérica hallada en Uxama (Soria)", Actas del III Coloquio, 311-7.

GAUTHIER, P. 1972: SYMBOLA. Les étrangers et la justice dans les cités grecques, Nancy.

GIL, J. 1977: «Notas a los bronces de Botorrita y Luzaga», Habis 8, 161-174.

Gómes, M. Varela y Beirão, C. de Mello 1988: «O tesouro da colecçâo Barros e Sá, Monsanto da Beira (Castelo Branco)», Veleia 5, 125-36.

Gómez-Moreno, M. 1949: Sup. $=\ll$ Suplemento de epigrafia ibérica», Misceláneas, 283-330.

- 1949: Misceláneas. Historia, Arte, Arqueología. Primera serie: la antigüedad, Madrid.

González Fernández, J. ed. 1994: Roma y las provincias. Realidad administrativa e ideología imperial, Madrid.

Gorrochategui, J. 1990: «Consideraciones sobre la fórmula onomástica y la expresión del origen en algunos textos celtibéricos menores", Studia Tovar et Michelena, 291-312.

Harris, W. V. 1989: Ancient Literacy, Cambridge, Mass.

HAVELOCK, E. A. 1981 (=1978): «L'alfabetizzazione di Omero", E. A. Havelock \& J. P. Hershbell, 1981, Arte e comunicazione.

Havelock, E. A. y Hershbel.t, J. P. 1981: Arte e comunicazione nel mondo antico. Roma-Bari = 1978, Communication Arts in the Ancient Word. Nueva York.

Hernandiz. Hernandez, F. 1985: «Nuevos grafitos de Extremadura", NAH 20, 221-4.

Hernándiz Hernández, F.; Rodriguez, M. a D. y Sán(HEz, M.a A. 1989: Excavaciones en el Castro de Villasviejas de Tamuja (Botija, Cáceres), Mérida.

Hernandiz. Vera, J. A. y Núñzz Marcen J. 1989: «Un nuevo antropónimo indigena, sobre cerámica, procedente de Graccurris», Veleia 6, 207-14.

Hispano-Gallo-Brittonica. Essays in honour of Prof. D. Ellis Evans: 1995: Ed.by J. F. Eska, R. G. Gruffydd, N. Jacobs, Cardiff.

Hoz, J. DE 1979: «Escritura e influencia clásica en los pueblos prerromanos de la Península», AEArq 52, 227-250.

- 1982: «Crónica de Lingüística y epigrafia de la Peninsula Ibérica: 1981», Zephyrus 34/35, 299 323.

- 1986: «La epigrafia celtibérica», Reunión sobre epigrafia, 43-102.

- 1988: «Hispano-celtic and Celtiberian», G. W. MacLennan ed., Proceedings, 191-207.

- 1993: «La lengua y la escritura ibéricas, y las lenguas de los íberos», Actas del V Coloquio, 635-666.

- 1993: «Testimonios lingüísticos relativos al problema céltico en la Peninsula lbérica», M. Almagro ed., Los celtas, 357-407.

- 1993: «Las sociedades paleohispánicas del área no indoeuropea y la escritura", AEArq 66, 3-29.

- 1994: «Griegos e íberos. Testimonios epigráficos de una cooperación mercantil», Iberos y Griegos II, 243-271.

- 1995: «Escrituras en contacto: ibérica y latina», Roma y el nacimiento, 57-84.

- en prensa, «La inscripción en escritura del S.O. de la estela de Almoroqui».

- en prensa: «El poblamiento antiguo de los Pirineos desde el punto de vista lingüístico», I Simposi de Poblament dels Pirineus, Andorra.

- en prensa: «Paleohispanic societies and writing», Archaeology today. Social Complexity and Change, Universidade do Algarve.

- en prensa: «Panorama provisional de la epigrafia 
rupestre paleohispanican, Saxa Scripla, Santiago de Compostela.

- en prensa: "Areas lingüisticas y lenguas vehiculares en el Mediterráneo occidental», L'Italia e il Mediterraneo antico.

- en prensa: "Tartesio, fenicio y céltico, 25 años después", Tartessos 25 años después, Jerez de la Frontera.

- en prensa: «The Botorrita first text. Its epigraphical background". Die grösseren altkeltischen Sprachdenkmäler, Innsbruck.

Ho/, J. de y Michtlina, L. 1974: La inscripción celtibérica de Botorrita. Salamanca.

HübNER, E. 1893: Monumenta Linguae Ibericae, Berlin (= MLI).

Iberos y griegos: lecturas desde la diversidad I-II: 1994: Coordinadores P. Cabrera, R. Olmos y E. Sanmarti, Huelva (= Huelva arqueológica XIII I y 2).

ILLRP = Degrassi, A.: 1965², 1963: Inscriptiones .

Indogermanica et Caucasica. Festschrift für Karl Horst Schmidt zum 65. Gehurstag: 1994: Herausgegeben von R. Bielmeier und R. Stempel, Berlin-Nueva York.

KODDERITZSCH, R. 1985: «Die große Felsinschrift von Peñalba de Villastar», Sprachwissenschaftliche Forschungen. Festschrift für J. Knobloch, Innsbruck, 211-222.

LABEAGA, J. C. 1987: «Amuletos mágicos y téseras de hospitalidad en los yacimientos arqueológicos de Viana", Primer Congreso General de Historia de Navarra (1986) 2, Pamplona, 453-463.

LAbeaga, J. C. y Untermann, J. 1993/94: «Las téseras del poblado prerromano de La Custodia, Viana (Navarra). Descripción, epigrafía y lingüistica», Trabajos de arqueologia navarra 11, 45-53.

Lejeune, M. 1955: Celtiberica. Salamanca.

- 1973: «La grande inscription celtibère de Botorrita», CRAI 1973, 622-647.

LUJÁN, E. R. en prensa: «La onomástica celtibérica: actualización y aspectos comparativos», Veleia.

Maluquer de Motes, J. 1968: Epigrafia prelatina de la Península Ibérica, Barcelona.

- 1974: «El bronce escrito de Botorrita (Zaragoza)», Pyrenae 10, 151-164.

MARCO, F. 1976: «Nuevas estelas ibéricas de Alcañiz (Teruel)", Pyrenae 12, 73-90.

- 1978: Las estelas decoradas de los Conventos Caesaraugustano y Cluniense, Zaragoza.

MARINER, S. 1976: "Botorrita, topónimo prelatino», Actas del I Coloquio, 49-55.

Martin Bueno, A. 1968: «Pesas de telar de Bilbilis», Caesaraugusta 31/32, 257-259.

Martin Valls, R. 1984: «Prehistoria palentina», en
Historia de Palencia I, dirigida por J. González, Madrid.

MeII, W. 1993: Die Erste Botorrita-Inschrift. Interpretation eines keltiberischen Sprachdenkmals, Innsbruck.

- 1994: "Die "große» Felsinschrift von Peñalba de Villastar", Indogermanica et Caucasica, 385-94.

- 1994: Celtiberian Inscriptions, Budapest.

MLH = Untermann, 1975.... Monumenta.

MLI = Hübner, 1893, Momumenta.

Moтt A, F. 1980: «Per un 'interpretazione della faccia B dil bronzo di Botorrita", AIWN 2, 99-123.

- 1980: «Onomastica Contrebiense», AIWN 2, 125147.

Mouri, J. A. y Garcin Soto, E. 1986: «Los grabados de la cueva de San Garcia, Sto. Domingo de Silos (Burgos)», Numantia 2, 193-206.

Paulsen, R. 1931: Numantia II: Die Stadt Numantia, Munich.

Pérez Ballester, J. 1992: «El abrigo de Reiná (Alcalá del Júcar). Ensayo sobre un nuevo modelo de lugar de culto en época ibérica», Estudios... E. Pla, 289-300.

Porta, E. 1982: «La restauración del bronce de Botorrita», en Beltrán-Tovar, 1982, Contrebia Belaisca 1, 87-91, Zaragoza.

Reunión sobre epigrafia hispánica de época romano-republicana: 1986: Zaragoza.

Roma y el nacimiento de la cultura epigráfica en Occidente: 1995: F. Beltrán editor, Zaragoza.

Romero, F. 1976: Las cerámicas policromas de Numancia, Soria.

Romero, F. y Elorza, J. C. 1990: «Nueva tésera celtibérica en la provincia de Burgos», BSAA 56 , 189-204.

Romero, M. ${ }^{a}$ V.a 1985: Numancia I. La Terra Sigillata, EAE 146, Madrid.

SÁnchez AbAl, J. L. y S. García Jiménez: 1988: «La ceca de Tanusian, Actas del $I^{\circ}$ Congreso peninsular, 149-189.

SchMid, K. H. 1972 (1976): «Der Beitrag der keltiberischen Inschrift von Botorrita zur Rekonstruktion der protokeltischen Syntax», Word 28, 51-62.

- 1976 «Zur keltiberischen Inschrift von Botorrita), $B B C S$ 26, 375-394. Cardiff.

- 1976: «Historich-vergleichende Analyse des der keltiberischen Inschrift von Botorrita zugrundeliegenden Morpheminventars"), Studies in Greek, Italic and Indoeuropean Linguistics, offered to L.R. Palmer ${ }_{2}$ 359-371. Innsbruck.

- 1992: «Problems of Celtiberian», Studia Celtica Japonica 5, 37-75.

SCHWERTECK, H. 1979: «Zur Deutung der großen Felsinschrift von Peñalba de Villastar», Actas del II Coloquio, 185-196. Salamanca.

SILVA A. C. F. DA 1983: «As tesserae hospitales do 
Castro da Senhora da Saúde ou Monte Murado (Pedroso, V. N. Gaia)", Gaia 1, 9-26.

II Simposium sobre los celtiheros: 1990: Necrópolis celtibéricas, Zaragoza.

Sol.IN, H. 1982: Die griechischen Personennamen in Rom. Ein Namenbuch, Berlin.

Sprachen und Schriften des antiken Mittelmeerraums. Festschrift für. Jürgen Untermann zum 65. Geburtstag: 1993: Innsbruck.

Striz, B. 1984: Literacy in Theory and Practice. Cambridge.

Studia indogermanica et palaeohispanica in honorem A. Tovar et L. Michelena: 1990: Editado por F. Villar, Salamanca.

Sup. Vid. M. Gómez Moreno.

Symbolae Ludovico Mitxelena septuagenario oblatae, J. L. Melena ed., Vitoria 1985.

Thomas, R. 1989: Oral Tradition and Written Record in Classical Athens, Cambridge.

Tovar, A. 1946: «Las inscripciones ibéricas y la lengua de los celtiberos", $B R A E 25,7-42$ (= 1949: Estudios, 21-60).

- 1948: «El bronce de Luzaga y las tesseras de hospitalidad latinas y celtibéricas", Emerita 16. 75-91 (=Estudios, 168-183).

- 1949: Estudios sobre las primitivas lenguas hispánicas, Buenos Aires.

- 1956: «La inscripción grande de Peñalba de Villastar y la lengua celtibérica», Ampurias $17 / 18$, 159-168. (=1973: Sprachen, 393-404.

- 1958: «Das Keltiberische, ein neuer Zweig des Festlandkeltischen», Kratylos 3, 1-14.

- 1959: «Las inscripciones celtibéricas de Peñalba de Villastar», Emerita 27, 349-65.

- 1960: «Lenguas indoeuropeas: testimonios antiguos»), ELH 101-26 (recogido en 1961: The Ancient Languages).

- 1961: The Ancient Languages of Spain and Portugal. Nueva York (cf. 1960: ELH).

- 1973: «Las inscripciones de Botorrita y de Peñalba de Villastar y los límites orientales de los celtíberos», Hispania Antiqua 3, 367-405.

- 1975: «Ein neues Denkmal der keltiberischen Sprache: die Bronze von Botorrita", ZcPh 34, 1-19.

- 1983: «Una nueva pequeña tésera celtibérica», Emerita 51, 1-3.

UnteRmanN, J. 1964: «Zur Gruppierung der hispanischen Reitermünzen mit Legenden in iberischer Schrift», MMitt 5, 91-155.

- 1967: «Zur Endung des Genitiv singularis der -o-Stämme im Keltiberischen», Beiträge zur Indogermanistik und Keltologie, Julius Pokorny zum 80. Geburstag gewidmet, 281-288. Innsbruck.

- 1975/1980/1990: Monumenta Linguarum hispa- nicarum. I. Die Münzlegenden. II. Inschriften in iherischer Schrift aus Südfrankreich. III. Die iberischen Inschriften aus Spanien, Wiesbaden.

- 1977: «En torno a las inscripciones rupestres de Peñalba de Villastar», Teruel 57/58, 5-21.

- 1980: «Namenkundliche Anmerkungen zu lateinischen Inschriften aus Kantabrien", $B N F$ 15,367392.

- 1983: «Die Keltiberer und das Keltiberische», E. Campanile ed., Prohlemi di lingua e di cultura nel campo indoeuropeo, Pisa,109-127.

- 1984: «Die Münzprägungen der Keltiberer». Keltische Numismatik und Archaeologie(Würzburg, 1981), Hrsg. v. G. Graasmann, W. Janssen, M. Brandt. Oxford, 431-472.

- 1987: «Lusitanisch, Keltiberisch, Keltisch», Actas del IV Coloquio, 57-76.

- 1989: «arganto- "Silber" im Keltiberischen; mit einem Beitrag von W. Bayer", Indogermanica Europaea. Festschrift für Wolfgang Meid, Graz, $431-450$

- 1990: "Comentarios sobre inscripciones celtibéricas 'menores'), Studia indogermanica, 351-374.

- 1994: "Anotaciones al estudio de las lenguas prerromanas del Noroeste de la Peninsula Ibérica», Galicia: da romanidade, 367-397.

- 1995: «Epigrafia indigena y romanización en la Celtiberia», Roma y el nacimiento, 197-208.

-en prensa: "Lengua y poblamiento prerromano en el territorio celtibérico", III Simposium sobre los celtiberos (Daroca 1991), Zaragoza.

VelazA, J. 1989: «A propósito de las téseras de hospitalidad de Viana», Veleia 6, 193-197.

Vetter, E. 1953: Handbuch der italischen Dialekte, Heidelberg.

Vicente, J. D.; Punter, M. a P.; Escriche, C. y HerCE, A. I. 1993: «Las inscripciones de la «Casa de LIKINE» (Caminreal, Teruel)", Actas del V Coloquio, 747-72.

VILLAR, F. 1989=1990: «Tratamiento de -o-en sílaba final. Algunas posibles formas de imperativo en celtibérico», Veleia $6,199-205=$ «Sur le traitement de -o- final et sur quelques formes possibles d'imperatif en céltiberique», AI $\Omega$ N 12, 271-280.

- 1990: "La linea inicial del bronce de Botorrita», Studia...A. Tovar et L. Michelena, 375-392.

- 1991: «Le locatif celtibérique et le caractère tardif de la langue celtique dans l'inscription de Peñalba de Villastar», ZCP 44, 56-60.

- 1993: «Las silbantes en celtibérico», Actas del V Coloquio, 773-811.

- 1995: Estudios de celtibérico y de toponimia prerromana, Salamanca.

- 1995: «EI hidrónimo prerromano Tamusia, mo- 
derno Tamuja", Hispano-Gallo-Brittonica, 260277.

- en prensa: «Las últimas novedades acerca de la gramática celtibérica", Actas del VI coloquio, Salamanca.

- en prensa: «Nueva interpretación de las leyendas monetales celtibéricas», I Encuentro peninsular de numismática antigua, Madrid.

Villaronga, L. 1979: Numismática antigua de Hispania. Barcelona.

- 1990: «El hallazgo de monedas. El caso de Tanu- sia», Gaceta numismática 97/98, 79-85.

- 1994: Corpus Nummum Hispaniae ante Augusti Aetatem, Madrid.

Wal..ACF, R. E. 1984: The Sabellian Languages, The Ohio State University Ph. D.

WATtENBtRG, F. 1963: Las cerámicas indigenas de Numancia. Madrid.

WoOlf, G. 1994: "Power and the spread of writing in the West", Bowman \& Woolf eds., Literacy, 84-98. 